Article

\title{
A Vegetation Index to Estimate Terrestrial Gross Primary Production Capacity for the Global Change Observation Mission-Climate (GCOM-C)/Second-Generation Global Imager (SGLI) Satellite Sensor
}

Juthasinee Thanyapraneedkul $^{1, *}$, Kanako Muramatsu ${ }^{1}$, Motomasa Daigo ${ }^{2}$, Shinobu Furumi ${ }^{3}$, Noriko Soyama ${ }^{4}$, Kenlo Nishida Nasahara ${ }^{5}$, Hiroyuki Muraoka ${ }^{6}$, Hibiki M. Noda ${ }^{5}$, Shin Nagai ${ }^{7}$, Takahisa Maeda ${ }^{8}$, Masayoshi Mano ${ }^{9}$ and Yasuko Mizoguchi ${ }^{10}$

1 Kyousei Science Center for Life and Nature, Kita-uoya, Nishimachi, Nara 630-8506, Japan;

E-Mail: muramatu@ics.nara-wu.ac.jp

2 Faculty of Economics, Doshisha University, Kyoto 602-8580, Japan;

E-Mail:mdaigo@mail.doshisha.ac.jp

3 Graduate School of Department of Childcare and Education, Nara Saho College, Nara 630-8425, Japan; E-Mail: sfurumi@narasaho-c.ac.jp

4 Center for Research and Development of Liberal arts Education, Tenri University, Nara 632-0032, Japan; E-Mail: soyama@sta.tenri-u.ac.jp

5 Faculty of Life and Environment Sciences, University of Tsukuba, Ibaraki 305-8577, Japan; E-Mails: 24dakenlo@gmail.com (K.N.N.); hibiki.noda@gmail.com (H.M.N.)

6 Institute for Basin Ecosystem Studies, Gifu University, Gifu 501-1193, Japan; E-Mail:muraoka@green.gifu-u.ac.jp

7 Research Institute for Global Change, Japan Agency for Marine-Earth Science and Technology, Kanagawa 237-0061, Japan; E-Mail: nagais@jamstec.go.jp

8 National Institute of Advanced Industrial Science and Technology, Tsukuba, Ibaraki 305-8561, Japan; E-Mail: takahisa.maeda@aist.go.jp

9 National Institute for Agro-Environmental Sciences, Tsukuba 305-8604, Japan; E-Mail:mmano@niaes.affrc.go.jp

${ }^{10}$ Hokkaido Research Center, Forestry and Forest Products Research Institute, Hokkaido 062-8516, Japan; E-Mail: pop128@ffpri.affrc.go.jp

* Author to whom correspondence should be addressed; E-Mail: yok_japan@yahoo.com.

Received: 30 September 2012; in revised form: 14 November 2012 / Accepted: 16 November 2012 / Published: 23 November 2012 


\begin{abstract}
To estimate global gross primary production (GPP), which is an important parameter for studies of vegetation productivity and the carbon cycle, satellite data are useful. In 2014, the Japan Aerospace Exploration Agency (JAXA) plans to launch the Global Change Observation Mission-Climate (GCOM-C) satellite carrying the second-generation global imager (SGLI). The data obtained will be used to estimate global GPP. The rate of photosynthesis depends on photosynthesis reduction and photosynthetic capacity, which is the maximum photosynthetic velocity at light saturation under adequate environmental conditions. Photosynthesis reduction is influenced by weather conditions, and photosynthetic capacity is influenced by chlorophyll and RuBisCo content. To develop the GPP estimation algorithm, we focus on photosynthetic capacity because chlorophyll content can be detected by optical sensors. We hypothesized that the maximum rate of low-stress GPP (called "GPP capacity") is mainly dependent on the chlorophyll content that can be detected by a vegetation index (VI). The objective of this study was to select an appropriate VI with which to estimate global GPP capacity with the GCOM-C/SGLI. We analyzed reflectance data to select the VI that has the best linear correlation with chlorophyll content at the leaf scale and with GPP capacity at canopy and satellite scales. At the satellite scale, flux data of seven dominant plant functional types and reflectance data obtained by the Moderate-resolution Imaging Spectroradiometer (MODIS) were used because SGLI data were not available. The results indicated that the green chlorophyll index, $\mathrm{CI}_{\text {green }}\left(\rho_{\mathrm{NIR}} / \rho_{\text {green }}-1\right)$, had a strong linear correlation with chlorophyll content at the leaf scale $\left(\mathrm{R}^{2}=0.87, \mathrm{p}<0.001\right)$ and with GPP capacity at the canopy $\left(\mathrm{R}^{2}=0.78, \mathrm{p}<0.001\right)$ and satellite scales $\left(\mathrm{R}^{2}=0.72, \mathrm{p}<0.01\right)$. Therefore, $\mathrm{CI}_{\text {green }}$ is a robust and suitable vegetation index for estimating global GPP capacity.
\end{abstract}

Keywords: GCOM-C/SGLI; Vegetation index; Gross primary production; Photosynthesis; Chlorophyll content; Light-response curve; FluxNet

\title{
1. Introduction
}

Terrestrial ecosystems are major sinks in the global carbon cycle, sequestering carbon and slowing the increase in $\mathrm{CO}_{2}$ concentration in the atmosphere [1]. The amount of carbon removed from the atmosphere by vegetation via photosynthesis is the gross primary production (GPP). To understand vegetation activity, highly accurate estimation of GPP is important, and satellite remote sensing offers an efficient approach to estimate GPP globally. The Japan Aerospace Exploration Agency (JAXA) plans to launch the Global Change Observation Mission-Climate (GCOM-C) satellite carrying the second-generation global imager (SGLI) sensor in 2014 [2]. The SGLI sensor will observe seven spectral bands from the visible to the near infrared (NIR) with a spatial resolution $250 \mathrm{~m}$ for land area observations. The obtained data are planned to be used to estimate global GPP.

Many studies have estimated GPP based on the concept of the light-use efficiency (LUE) model [3] using satellite data [1,4-6]. In LUE models, GPP is calculated as the product of the maximum LUE $\left(L_{U E} E_{\max }\right)$, the reduction of $\mathrm{LUE}_{\max }$ due to environmental stress [7-9], the photosynthetically active 
radiation (PAR), and the fraction of PAR absorbed by the plant canopy (FPAR). LUE $E_{\max }$, the stress factor, and leaf area index (LAI) estimations are crucial to the LUE model. The LUE concept has been applied to diagnostic models for estimating GPP, such as the Biosphere Model Integrating Ecophysiological and Mechanistic Approaches Using Satellite Data (BEAMS) [10], as well as machine-learning techniques in conjunction with remote sensing data and flux tower data $[11,12]$. Another approach includes process-based models such as the Boreal Ecosystem Productivity Simulator (BEPS) [13], the two-leaf process-based BEPS model [14], and the Breathing Earth System Simulator (BESS) [15]. The two-leaf process-based BEPS model is an hourly process-based diagnostic model that computes canopy-level GPP as the sum of sunlit and shaded leaf groups [14]. The BESS model couples atmospheric and land processes including leaf photosynthesis, stomatal conductance, and transpiration of the sunlit and shaded portions of vegetation and soil [15]. However, the BESS model includes a major source of uncertainty that originates from satellite-derived LAI [15]. Zhang et al. [13] demonstrated that process-based models that separate sunlit and shaded leaves perform better than the

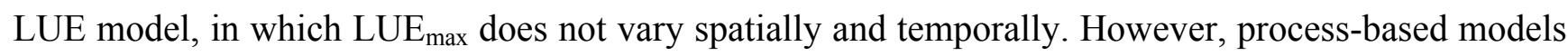
are more complex and require many parameters, whereas LUE models have the advantage of simplicity.

GPP is affected by seasonal changes in the maximum velocity of carboxylation $\left(\mathrm{V}_{\mathrm{cmax}}\right)$ [16-19]. The plant physiological parameter of $\mathrm{V}_{\mathrm{cmax}}$ is estimated using satellite-derived LAI. Therefore, it is worthwhile to directly extract the ecophysiological and physiochemical properties of vegetation from satellite data. To accomplish this, many vegetation indices (VIs) have been developed, such as those related to the chlorophyll content of a leaf or the canopy. One VI uses NIR and green reflectance to estimate the chlorophyll content of a rice canopy [20]. The photochemical reflectance index $\left(\mathrm{PRI}=\left[\mathrm{R}_{531}-\mathrm{R}_{570}\right] /\left[\mathrm{R}_{531}+\mathrm{R}_{570}\right]\right)$ [21] and the green ratio index $\left(\mathrm{GRI}=\mathrm{R}_{830} / \mathrm{R}_{550}\right)$ [22]) are used to estimate photosynthetic efficiency and capacity. VIs for estimating chlorophyll include the chlorophyll index, $C I=R_{880} / R_{\text {red-edge or green }}-1$ [23-28]; the chlorophyll content index, $C C I=D_{720} / D_{700}$ (where $D_{x}$ is the first derivative of reflectance at wavelength $x$ [29]); the red-edge position index (REP) [30]; the medium imaging spectrometer (MERIS) terrestrial chlorophyll index (MTCI) [31], which incorporates the REP index; the Transformed Chlorophyll Absorption in Reflectance Index/Optimized Soil-Adjusted Vegetation Index (TCARI [32]/OSAVI [33,34]) [32], which is sensitive to crop chlorophyll concentration and is used to minimize soil background effects; and the modified chlorophyll

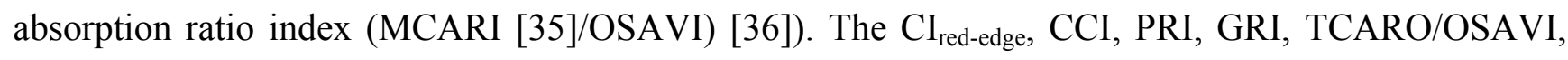
and MCARI/OSAVI are calculated from hyperspectral satellite sensor data such as those obtained by the Project for On-Board Autonomy (PROBA) satellite carrying a Compact High Resolution Imaging Spectrometer (CHRIS) and by the Earth-Observing 1 (EO-1) satellite carrying the Hyperion imaging spectrometer. These indices cannot be calculated from data retrieved by multispectral satellite sensors such as SGLI and MODIS.

Gitelson et al. [26,37] showed that total canopy chlorophyll content in crops is closely related to midday GPP, and Wu et al. [38] demonstrated the green CI exhibits a linear relationship with chlorophyll content; incident LUE (GPP/PAR) in the morning, which is related to total chlorophyll in the canopy [38-40]; and seasonal changes of incident LUE [4]. Using the chlorophyll index and incoming PAR, GPP was successfully estimated from LANDSAT data for crops [41] using MODIS data for deciduous and evergreen forest sites [42]. This GPP estimation method assumed a linear relationship between incoming PAR and GPP. 
Another global GPP estimation model that uses light-response curves has also been applied to VIs to estimate maximum photosynthesis under light saturation $\left(\mathrm{P}_{\max }\right)$ [43-45]. These studies have suggested that the VI should be linear to maintain sensitivity over as wide a range of $\mathrm{P}_{\max }$ as possible and to facilitate scaling and extrapolations across regional and global resolutions. The model, however, did not include weather conditions and used only a single shape of the light-response curve representing temperate vegetation in Japan. Ide et al. [46] analyzed the light-response curve by including weather conditions in a larch forest in Japan. They determined daily $\mathrm{P}_{\max }$ and the initial slope from seasonal and short-term variations. The seasonal variations in $\mathrm{P}_{\max }$ and initial slope were correlated with the ratio VI (RVI) or enhanced VI (EVI). These two research approaches estimated GPP using the light-response curve to examine the relationship between GPP and the VI. However, for global GPP estimation, the relationship between $\mathrm{P}_{\max }$ and VI should be determined more widely in other main biomes.

To estimate global GPP, photosynthesis of a single leaf is key. The leaf photosynthetic rate depends on photosynthetic capacity and photosynthesis reduction. Photosynthetic capacity is influenced by chlorophyll and RuBisCo (ribulose-1, 5-bisphosphate carboxylase/oxygenase) content [47]. Photosynthesis reduction is affected by microclimatic factors (i.e., air temperature and vapor pressure deficit) and stomatal opening and closing. The chlorophyll pigment absorbs light energy and converts it to chemical energy, and RuBisCo is an enzyme involved in the first major step of carbon fixation [48]. Chlorophyll pigment has the greatest chemical influence on a leaf's spectral properties [49] and can be detected by an optical sensor [50]. However, photosynthesis reduction, which fluctuates in the short term (from seconds to minutes), is difficult to detect by an optical sensor alone and may require different techniques. Therefore, we focused on leaf chlorophyll content to estimate leaf photosynthetic capacity.

At the canopy scale, photosynthetic capacity is the integration of single-leaf chlorophyll content and the total leaf area [51]. Recent research has suggested that it is better to consider leaf angle distribution in the analysis of canopy photosynthesis [16]. We considered canopy photosynthetic capacity as the integration of leaf photosynthetic capacity for the effective leaf area exposed to light. The effective leaf area varies due to canopy structure and leaf angle distribution. We hypothesized that the maximum canopy photosynthesis rate in low-stress conditions is mainly dependent on the total leaf chlorophyll content of the effective leaf area. The objective of this study was to select an appropriate VI to estimate global GPP capacity (photosynthetic capacity) based on the light-response curve concept using GCOM-C/SGLI data (note that SGLI data are not yet available).

\section{Methods}

\subsection{VI for Estimating the Maximum Rate of Low-Stress GPP}

We defined the GPP under low-stress conditions as GPP capacity. The light-response curve under low-stress conditions using a rectangular hyperbolic function is described as:

$$
\mathrm{GPP}_{\text {capacity }}(\mathrm{PAR})=\frac{\mathrm{P}_{\text {max _capactiy }} \times \alpha_{\text {slope }} \times \mathrm{PAR}}{\left(1+\alpha_{\text {slope }} \times \mathrm{PAR}\right)},
$$

where $\mathrm{GPP}_{\text {capacity }}\left(\mathrm{mg} \cdot \mathrm{CO}_{2} \cdot \mathrm{m}^{-2} \cdot \mathrm{s}^{-1}\right)$ is the low-stress GPP, $\mathrm{P}_{\text {max capacity }}\left(\mathrm{mg} \cdot \mathrm{CO}_{2} \cdot \mathrm{m}^{-2} \cdot \mathrm{s}^{-1}\right)$ is the

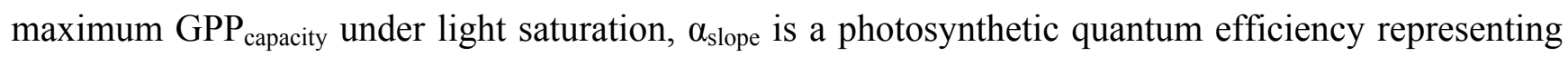


the initial slope of the light-response curve, and PAR $\left(\mu \mathrm{mol} \cdot \mathrm{m}^{-2} \cdot \mathrm{s}^{-1}\right)$ is photosynthetically active radiation (Figure 1).

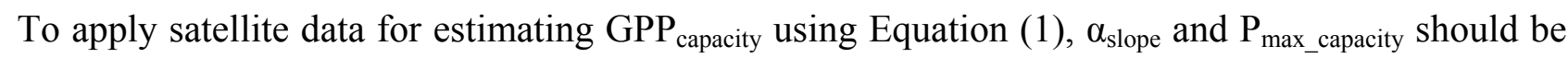
determined. Leaf physiological research has revealed that the initial slope of the light-response curve depends on the efficiency of light conversion into fixed carbon [52] and the chlorophyll concentration. Furthermore, analysis of flux data has shown that the initial slope of a light-response curve derived from a non-rectangular hyperbolic function changes under different weather conditions; however, the initial slope and $\mathrm{P}_{\max }$ both exhibit a linear relationship with the same VI [46], suggesting that the initial slope and $\mathrm{P}_{\max }$ are linearly correlated. On the other hand, other studies have reported that $\mathrm{P}_{\max }$ is related to the amount of chloroplasts [53,54]. From these findings, we in order to reduce the number of parameters, we assume that $\alpha_{\text {slope }}$ is a constant for each plant functional type. In addition, we assume that $\mathrm{P}_{\text {max capacity }}$ is related to the amount of chlorophyll. From this perspective, we examined the method and VI for estimating $P_{\text {max }}$ capacity from satellite data.

First, we examined spectral reflectance to select potential candidate VIs that show linear correlations with chlorophyll content from a set of VIs. Second, we studied the relationship between candidate VIs and $\mathrm{P}_{\max }$ capacity of canopy light-response curves under low-stress conditions. Finally, the selected VI was validated.

Figure 1. Canopy light-response curve. Low-stress global gross primary production $\left(\mathrm{GPP}_{\text {capacity }}\right)\left(\mathrm{mg} \cdot \mathrm{CO}_{2} \cdot \mathrm{m}^{-2} \cdot \mathrm{s}^{-1}\right)$ is the low-stress GPP, $\mathrm{P}_{\text {max capacity }}\left(\mathrm{mg} \cdot \mathrm{CO}_{2} \cdot \mathrm{m}^{-2} \cdot \mathrm{s}^{-1}\right)$ is the maximum $\mathrm{GPP}_{\text {capacity }}$ under light saturation, and $\alpha_{\text {slope }}$ is photosynthetic quantum efficiency representing the initial slope of the light-response curve.

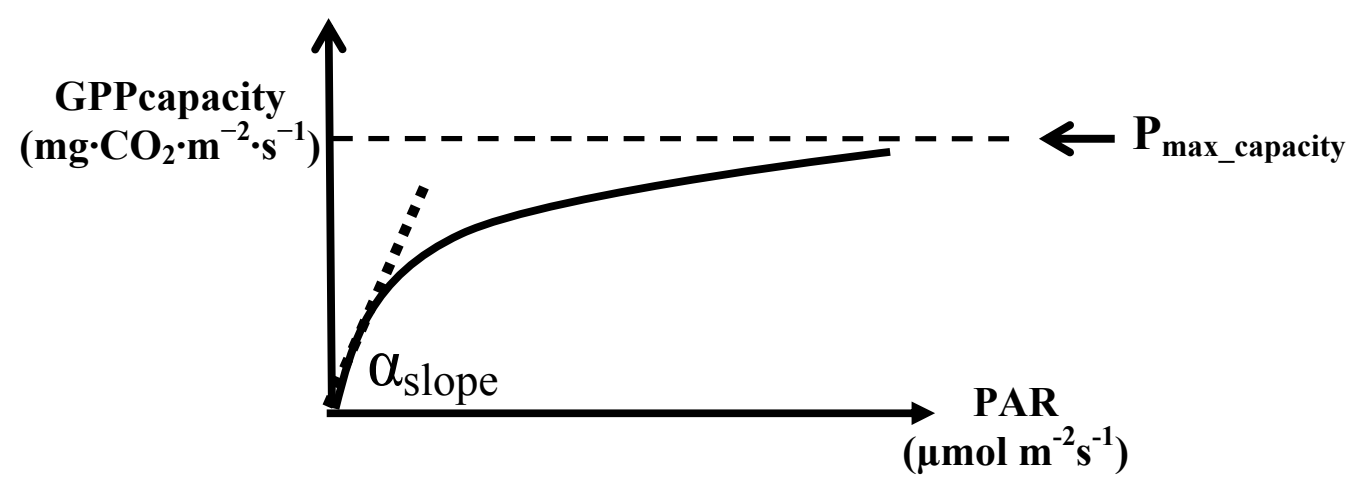

\subsection{Selection of Vegetation Indices (VIs)}

At leaf and canopy scales, we resampled spectral reflectance for the following spectral bands of GCOM-C/SGLI: blue ( $\left.\rho_{\text {blue }} ; 438-448 \mathrm{~nm}\right)$, green $\left(\rho_{\text {green }} ; 520-540 \mathrm{~nm}\right)$, red $\left(\rho_{\text {red }} ; 663.5-683.5 \mathrm{~nm}\right)$, and NIR ( $\left.\rho_{\mathrm{N} I R} ; 858.5-878.5 \mathrm{~nm}\right)$, as summarized in Table 1. At the satellite scale, we used data from the MODIS sensor on board the TERRA satellite (MOD09A1.005; 8-day land-surface reflectance). The wavelengths of TERRA/MODIS are summarized in Table 1. We used MODIS sensor data in this study because MODIS is the most similar sensor to SGLI in that both have a short repeat cycle (2-4 days), wide swath $(>2,000 \mathrm{~km})$, high radiance resolution, moderate spatial resolution $(1 \mathrm{~km} / 250 \mathrm{~m})$, and spectrally similar bands. 
Table 1. Global Change Observation Mission-Climate (GCOM-C)/ second-generation global imager (SGLI) and TERRA/MODIS spectral bands (showing only bands 1 to 4).

\begin{tabular}{ccccc}
\hline & GCOM-C/SGLI & & TERRA/MODIS & \\
Band Name & Wavelength (nm) & Width & Wavelength (nm) & Width \\
\hline$\rho_{\text {blue }}$ & 443 & 10 & 469 & 20 \\
$\rho_{\text {green }}$ & 530 & 20 & 555 & 20 \\
$\rho_{\text {red }}$ & 673.5 & 20 & 655 & 50 \\
$\rho_{\text {NIR }}$ & 868.5 & 20 & 858.5 & 35 \\
\hline
\end{tabular}

Gitelson et al. [50] suggested that chlorophyll concentration can be derived using reflectance at $550 \mathrm{~nm}\left(\rho_{\text {green }}\right)$ and $675 \mathrm{~nm}\left(\rho_{\text {red }}\right)$. For low chlorophyll concentrations, the reflectance sensitivity is higher at the maximum absorption located around $675 \mathrm{~nm}\left(\rho_{\text {red }}\right)$. At medium to high concentrations, reflectance sensitivity is higher at $550 \mathrm{~nm}\left(\rho_{\text {green }}\right)$. Thus, we selected several VIs that may relate to chlorophyll content. Moreover, it better to select the VI which has the best linear relationship with chlorophyll content to estimate GPP at the global scale. Because the uncertainty involved in aggregating remote sensing data from smaller to larger spatial scales (up-scaling) is related both to non-linearity in the response function and to heterogeneity within a site. When the response is non-linear, conventional averaging of reflected radiation gives a biased estimate of photosynthesis [49]. Spectral reflectance data were used to calculate VIs as illustrated in the following Equations (2) to (8):

(1) The NDVI [55] is the most widely used index for many vegetation applications. However, the NDVI has a saturation problem with very dense vegetation.

$$
\mathrm{NDVI}=\frac{\rho_{\mathrm{NIR}}-\rho_{\mathrm{red}}}{\rho_{\mathrm{NIR}}+\rho_{\mathrm{red}}}
$$

(2) The enhanced VI (EVI) [56] is an improved VI that accounts for the effects of residual atmospheric contamination and soil background. The EVI reduces the saturation problem in various canopies.

$$
\mathrm{EVI}=\frac{2.5\left(\rho_{\mathrm{NIR}}-\rho_{\mathrm{red}}\right)}{\left(\rho_{\mathrm{NIR}}+6 \rho_{\mathrm{red}}-7.5 \rho_{\text {blue }}+1\right)}
$$

(3) The modified NDVI (mNDVI) [57] was developed to eliminate the effects of surface reflectance by incorporating the blue band. This VI is more strongly correlated with total chlorophyll and eliminates the effect of surface reflectance.

$$
\operatorname{mNDVI}=\frac{\rho_{\mathrm{NIR}}-\rho_{\text {red }}}{\rho_{\mathrm{NIR}}+\rho_{\text {red }}-2 \rho_{\text {blue }}}
$$

(4) The green and red ratio VI (GRVI) [58] was proposed as an index to monitor the photosynthetically active biomass of plant canopies. The GRVI is calculated from the visible green and red reflectance.

$$
\text { GRVI }=\frac{\rho_{\text {green }}-\rho_{\text {red }}}{\rho_{\text {green }}+\rho_{\text {red }}}
$$

(5) The simple ratio index (SR) [59] is probably the first index and is the most commonly used to derive LAI for a forest canopy. 


$$
\mathrm{SR}=\frac{\rho_{\mathrm{NIR}}}{\rho_{\text {red }}}
$$

(6) The green NDVI (GNDVI) [50] is a better VI at a higher LAI and is good at detecting chlorophyll. The GNDVI can detect a wider range of chlorophyll compared to the NDVI.

$$
\text { GNDVI }=\frac{\rho_{\mathrm{NIR}}-\rho_{\text {green }}}{\rho_{\mathrm{NIR}}+\rho_{\text {green }}}
$$

(7) The green chlorophyll index (CI $\mathbf{I}_{\text {green }}$ ) [25] is sensitive to a wide range of chlorophyll variation. $\mathrm{CI}_{\text {green }}$ can estimate canopy chlorophyll content under a wide range of canopy conditions.

$$
\mathrm{CI}_{\text {green }}=\frac{\rho_{\mathrm{NIR}}}{\rho_{\text {green }}}-1
$$

\subsection{Data Sets}

To investigate relationships between VIs and photosynthesis capacity, data at three scales were used: leaf, canopy, and satellite scales.

\subsubsection{Leaf-Scale Data Set}

Data sets of the chlorophyll content $\left(\mu \mathrm{g} \cdot \mathrm{cm}^{-2}\right)$ of 19 sampled leaves (minimum chlorophyll content of $0.88 \mu \mathrm{g} \cdot \mathrm{cm}^{-2}$, maximum of $50.76 \mu \mathrm{g} \cdot \mathrm{cm}^{-2}$, average of $16.08 \mu \mathrm{g} \cdot \mathrm{cm}^{-2}$, standard deviation of $14.56 \mu \mathrm{g} \cdot \mathrm{cm}^{-2}$ ) were used, and reflectance data with a spectral range of 350 to $2,500 \mathrm{~nm}$, were obtained from Furumi et al. [60] for 20 types of leaves measured in various states (fresh green, yellowish green, yellow, red, and dead leaves).

\subsubsection{Canopy-Scale Data Set}

Eddy covariance (EC) flux data and canopy spectral reflectance of broadleaf deciduous trees at a site in Takayama, Japan, were used. The EC flux data for 2003 and 2004 were used to calculate $\mathrm{P}_{\text {max capacity }}$ from the light-response curve. These data were downloaded from AsiaFlux (http://asiaflux.yonsei.kr/) and included the net ecosystem exchange (NEE; $\mu \mathrm{mol} \cdot \mathrm{CO}_{2} \cdot \mathrm{m}^{-2} \cdot \mathrm{s}^{-1}$ ), friction velocity $\left(\mathrm{U}^{*} ; \mathrm{m} \cdot \mathrm{s}^{-1}\right)$, photosynthetic photon flux density $\left(\mathrm{PAR} ; \mathrm{mol} \cdot \mathrm{m}^{-2} \cdot \mathrm{s}^{-1}\right)$, net radiation $(\mathrm{Rn}$; $\left.\mathrm{W} \cdot \mathrm{m}^{-2}\right)$, air temperature $\left(\mathrm{T}_{\text {air }} ;{ }^{\circ} \mathrm{C}\right)$, relative humidity $(\mathrm{Rh} ; \%)$, soil temperature $\left(\mathrm{T}_{\text {soil }} ;{ }^{\circ} \mathrm{C}\right)$, vapor pressure deficit (VPD; $\mathrm{kPa}$ ), and precipitation (PPT; $\mathrm{mm}$ ). Precipitation data were provided by the Institute for Basin Ecosystem Studies, Gifu University, Japan. Respiration, NEE, and GPP data were provided by the National Institute for Environmental Studies (NIES). The data had a time interval of $30 \mathrm{~min}$.

For canopy reflectance, data measured by a hemispherical spectroradiometer (HSSR; MS-700, EKO Instruments Co., Ltd.) in 2004 were used. The HSSR had a spectral range of 350 to $1,050 \mathrm{~nm}$ and spectral interval of $3.3 \mathrm{~nm}$. The data were downloaded from the PEN website (http://www.pheno-eye.org/) [61]. 
Table 2. Description of the study sites representing seven plant functional types.

\begin{tabular}{|c|c|c|c|c|c|c|c|}
\hline Site Name & CA-Let & JP-TMK & JP-TKY & JP-Mase & JP-FJY & US-Dk1 & TH-SKR \\
\hline (data year) & 2002,2003 & 2002,2003 & 2003, 2004 & 2002,2003 & 2003, 2004 & ) 03 & 2002,2003 \\
\hline City & Lethbridge & Hokkaido & Takayama & Tsukuba & Yamanashi & $\mathrm{Nc}$ & Sakaerat \\
\hline Country & Canada & Japan & Japan & Japan & Japan & US. & Thailand \\
\hline Latitude & $49.709^{\circ} \mathrm{N}$ & $42.737^{\circ} \mathrm{N}$ & $36.146^{\circ} \mathrm{N}$ & $36.054^{\circ} \mathrm{N}$ & $35.454^{\circ} \mathrm{N}$ & $35.971^{\circ} \mathrm{N}$ & $14.492^{\circ} \mathrm{N}$ \\
\hline Longitude & $-112.940^{\circ} \mathrm{W}$ & $141.519^{\circ} \mathrm{E}$ & $137.423^{\circ} \mathrm{E}$ & $140.027^{\circ} \mathrm{E}$ & $138.762^{\circ} \mathrm{E}$ & $-79.093^{\circ} \mathrm{W}$ & $101.916^{\circ} \mathrm{E}$ \\
\hline Plant Functional Types & $\mathrm{C} 3$ grass, arctic & NDT & BDT,Temperate & Crop & NET, Temperate & $\mathrm{C} 3$ grass & BET,Tropical \\
\hline Dominant species & $\begin{array}{l}\text { Short/mixed grass } \\
\text { prairie }(\mathrm{C} 3 / \mathrm{C} 4)\end{array}$ & $\begin{array}{l}\text { Japanese } \\
\text { Larch }\end{array}$ & $\begin{array}{l}\text { Deciduous Oak, } \\
\text { Birch }\end{array}$ & Rice & $\begin{array}{l}\text { Japanese red } \\
\text { pine }\end{array}$ & $\begin{array}{l}\text { Tall fescue,C3 } \\
\text { grass and forbs }\end{array}$ & Dipterocarp \\
\hline Tree age (years) & - & 45 & 50 & - & 90 & 1 & - \\
\hline Elevation (m) & 960 & 140 & 1420 & 13 & 1030 & 163 & 535 \\
\hline Canopy height (m.) & - & 16 & $15-20$ & 1.2 & 20 & $0.1-1$ & 35 \\
\hline $\begin{array}{l}\text { Flux measurement } \\
\text { height (m) }\end{array}$ & 4 & 27 & 25 & 3 & 25.4 & 3 & 45 \\
\hline $\begin{array}{l}\text { Annual } \\
\text { avg. air temp. }\left({ }^{\circ} \mathrm{C}\right)\end{array}$ & 5.36 & 6.61 & 7.2 & 12.9 & 10.1 & 15.5 & 24.1 \\
\hline$U^{*}$ threshold $(\mathrm{m} / \mathbf{s})$ & 0.2 & 0.3 & 0.5 & 0.1 & 0.12 & 0.2 & 0.2 \\
\hline Reference & $\begin{array}{l}\text { Gilmanov et al. } \\
2005\end{array}$ & $\begin{array}{l}\text { Hirata et al. } \\
2007\end{array}$ & $\begin{array}{l}\text { Muraoka et al. } \\
2005\end{array}$ & $\begin{array}{l}\text { Saito et al. } \\
2005\end{array}$ & $\begin{array}{l}\text { Mizoguchi et al. } \\
2012\end{array}$ & $\begin{array}{l}\text { Novick et al. } \\
2004\end{array}$ & $\begin{array}{l}\text { Aguilos et al. } \\
2007\end{array}$ \\
\hline
\end{tabular}

Plant Functional Types (PFTs) 1. NET, temperate $=$ Needleleaf Evergreen Temperate Trees 2. NDT $=$ Needleleaf Deciduous Trees 3. BET, Tropical $=$ Broadleaf Evergreen Tropical Trees

$=4 . \mathrm{BDT}$, Temperate $=$ Broadleaf Deciduous Temperate Trees, $\mathrm{U}^{*}=$ friction velocity. 
2.3.3. Satellite-Scale Data Set: EC Flux Data and MODIS Spectral Reflectance of Seven Plant Functional Types

Seven EC flux tower sites were selected from Bonan, 1996 [62]. These sites correspond to seven of dominant plant functional types. We selected study sites on the basis of online availability and accessibility of necessary parameters. Details of each site are summarized in Table 2. The study sites were representative of C3 grass, arctic (CA-Let); needleleaf deciduous trees (JP-TMK); broadleaf deciduous trees, temperate (JP-TKY); crop-paddy fields (JP-Mase); needleleaf evergreen trees, temperate (JP-FJY); C3 grass (US-Dk1); and broadleaf evergreen trees, tropical (TH-SKR).

All of the EC flux data were used to calculate $\mathrm{P}_{\text {max }}$ capacity using the light-response curve. The EC flux datasets were downloaded from the FluxNet project (http://daac.ornl.gov/FLUXNET/fluxnet.shtml) for the JP-Mase site, from AmeriFlux (http://public.ornl.gov/ameriflux) for the US-Dk1 site, from FluxNet Canada (http://www.fluxnet-canada.ca) for the CA-Let site, and from AsiaFlux (http://asiaflux.yonsei.kr/) for the JP-TMK and TH-SKR sites. For the JP-FJY site, original measurement data were downloaded from the Forestry and Forest Products Research Institute (FFPRI) [63]. Additionally, we used the level-2 product or original measurement data of AmeriFlux data to reduce errors that may arise in the gap-filling process. The downloaded data were the same parameters as those used for the canopy scale for JP-TKY. The time interval of the data was $30 \mathrm{~min}$.

All data for the year 2003 were used. To examine relationships between VIs and $\mathrm{P}_{\text {max }}$ capacity, 8-day composited level-3 global reflectance data from TERRA/MODIS (MOD09A1.005) with 500-m resolution were used. The datasets were downloaded from the Oak Ridge National Laboratory Distributed Active Archive Center (ORNL DAAC; http://daac.ornl.gov/MODIS/), which provides subsets of MODIS Land Products for any tower site in the global FluxNet network by area (from one pixel up to $201 \times 201 \mathrm{~km}$ ) and time period. From the subsets, one center pixel corresponding to the flux tower location was used.

\subsection{Data Processing}

Data processing included two main parts: the reflectance data process for calculating the VI and the photosynthetic capacity calculation processes. At the leaf scale, we analyzed the relationship between SGLI band reflectance and chlorophyll content. At the canopy scale, we analyzed the relationship

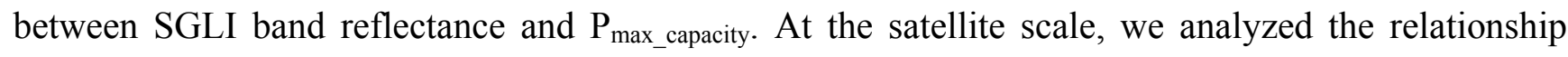
between MOD09A1 and $\mathrm{P}_{\max \text { _capacity. }} \mathrm{P}_{\text {max }}$ capacity was calculated from EC flux data by fitting the light-response curve.

\subsubsection{Reflectance Data Process}

At the leaf and canopy scales, the reflectance was averaged over the wavelength interval of the SGLI sensor (Table 1) to calculate VIs. At the canopy scale, HSSR data between 10:20 a.m. and 10:40 a.m. (Terra overpass time) were averaged for 16-day periods. At the satellite scale, values of band reflectance and quality assurance (QA) descriptions of the surface reflectance data were extracted from the MOD09A1.005 data [64]. Only data with 'no cloud shadow' and 'clear' cloud-state flags were used; data flagged as 'cloudy,' 'mixed,' and 'not set, assumed clear' were excluded. We then averaged 
8-day data to 16-day periods under the following conditions. If the cloud-state flag was 'clear' in both 8 -day periods, we used their average value. If 'not clear' appeared in only one dataset, we selected the 8-day period with the clear-state flag. If 'not clear' appear in both datasets, we discarded both datasets.

\subsubsection{Photosynthetic Capacity Calculation Processes}

\section{EC Flux Data Process for Selection of Low-Stress Data}

To identify criteria for selecting low-stress conditions, we investigated the diurnal change in net ecosystem production (NEP) by averaging half-hourly NEP over a 16-day period. We used a 16-day period to avoid strong confounding seasonal effects, to have a period long enough to provide sufficient data [65], and to decrease the number of spectral peaks and gaps captured in various types of ecosystem fluxes [66]. To find low-stress conditions, we then examined the VPD which is an important cause of the midday depression of net photosynthesis [67]. Therefore, we used half-hourly VPD averaged over 16-day periods to select low-stress conditions. The VPD threshold was determined when the midday depression of photosynthesis occurred in the diurnal NEP curve. Photosynthesis and midday depression [68] are shown in Figure 2, which categorizes pattern in the diurnal variation in photosynthesis into three types: (1) a single diurnal peak, which means that no stress occurs; (2) two diurnal peaks, which normally occur in nature; and (3) one peak with severe midday depression, which occurs mostly in drought areas. We used these three patterns to observe midday depression phenomena in the diurnal NEP curve.

Figure 2. Three patterns of diurnal variation in net ecosystem production for the photosynthesis. Pattern 1: a single diurnal peak, indicating that no stress occurs; Pattern 2: two diurnal peaks, which is a common occurrence in nature; and Pattern 3: one peak with severe midday depression, which occurs mostly in drought areas.

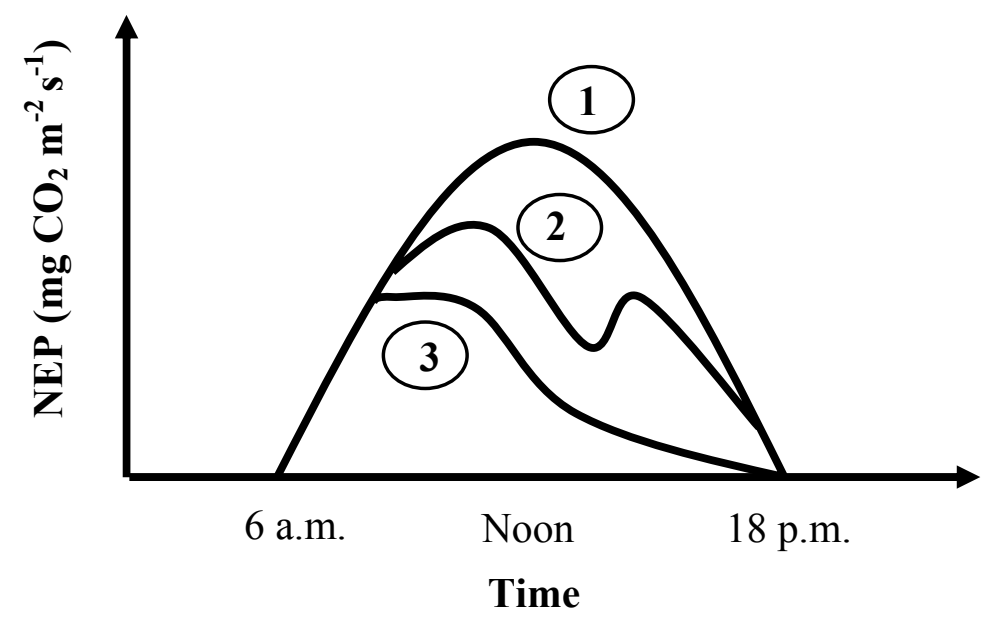

$\mathrm{P}_{\text {max_capacity }}$ Calculation

To draw the light-response curve, GPP capacity $_{\text {data }}$ were plotted against PAR. GPP data are typically provided by the FluxNet project. When GPP data were not provided by a flux tower, we calculated GPP as a sum of NEP and ecosystem respiration (Rec). Rec was estimated using nighttime NEP as a function of air temperature. Appendix describes the Rec estimation in detail. $\mathrm{P}_{\text {max }}$ capacity and $\alpha_{\text {slope }}$ were 
calculated from the light-response curve by fitting half-hourly $\mathrm{GPP}_{\text {capacity }}$ data (not averaged) for each

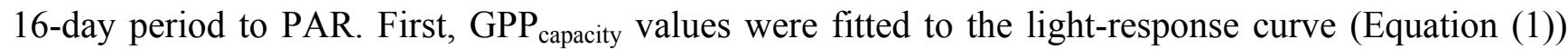
using the least-squares method as a function of PAR. Then, $P_{\text {max_capacity }}$ and $\alpha_{\text {slope }}$ were determined. $\mathrm{GPP}_{\text {capacity }}$ values were fitted again as a function of PAR to determine $\mathrm{P}_{\text {max } \_ \text {capacity }}$ using $\alpha_{\text {slope }}$ averaged from each 16-day photosynthesis period over the growing season. The photosynthesis periods used were those for which NEP in daytime was greater than zero.

\subsection{Validation of the VI}

To test the potential of the selected VI to estimate $\mathrm{P}_{\text {max }}$ capacity in a different year, we used the empirical relationship between the selected VI and $\mathrm{P}_{\text {max capacity }}$ of year 2003. The selected VI was calculated from MOD09A1 for the CA-Let, JPTMK, JP-Mase, and TH-SKR sites in 2002 and the JP-TKY and JP-FJY sites in 2004. We then compared estimated $\mathrm{P}_{\text {max }}$ capacity and observed $\mathrm{P}_{\text {max }}$ capacity.

\section{Results}

\subsection{Leaf Scale: Relationship between VIs and Chlorophyll Content}

The relationship between the reflectance at each SGLI spectral band and chlorophyll content is illustrated in Figure 3. $\rho_{\text {blue }}$ was stable at all chlorophyll contents, and $\rho_{\text {NIR }}$ was not sensitive to the chlorophyll content. $\rho_{\text {red }}$ and $\rho_{\text {green }}$ exhibited negative relationship with chlorophyll content. However, when chlorophyll content was more than $25 \mu \mathrm{g} \cdot \mathrm{cm}^{-2}, \rho_{\text {red }}$ remained constant. On the other hand, $\rho_{\text {green }}$ exhibited a strong negative relationship with chlorophyll content across a wide range from 0.3 to $50 \mu \mathrm{g} \cdot \mathrm{cm}^{-2}$.

Figure 3. Relationship between the reflectance at each SGLI spectral band and the leaf chlorophyll content.

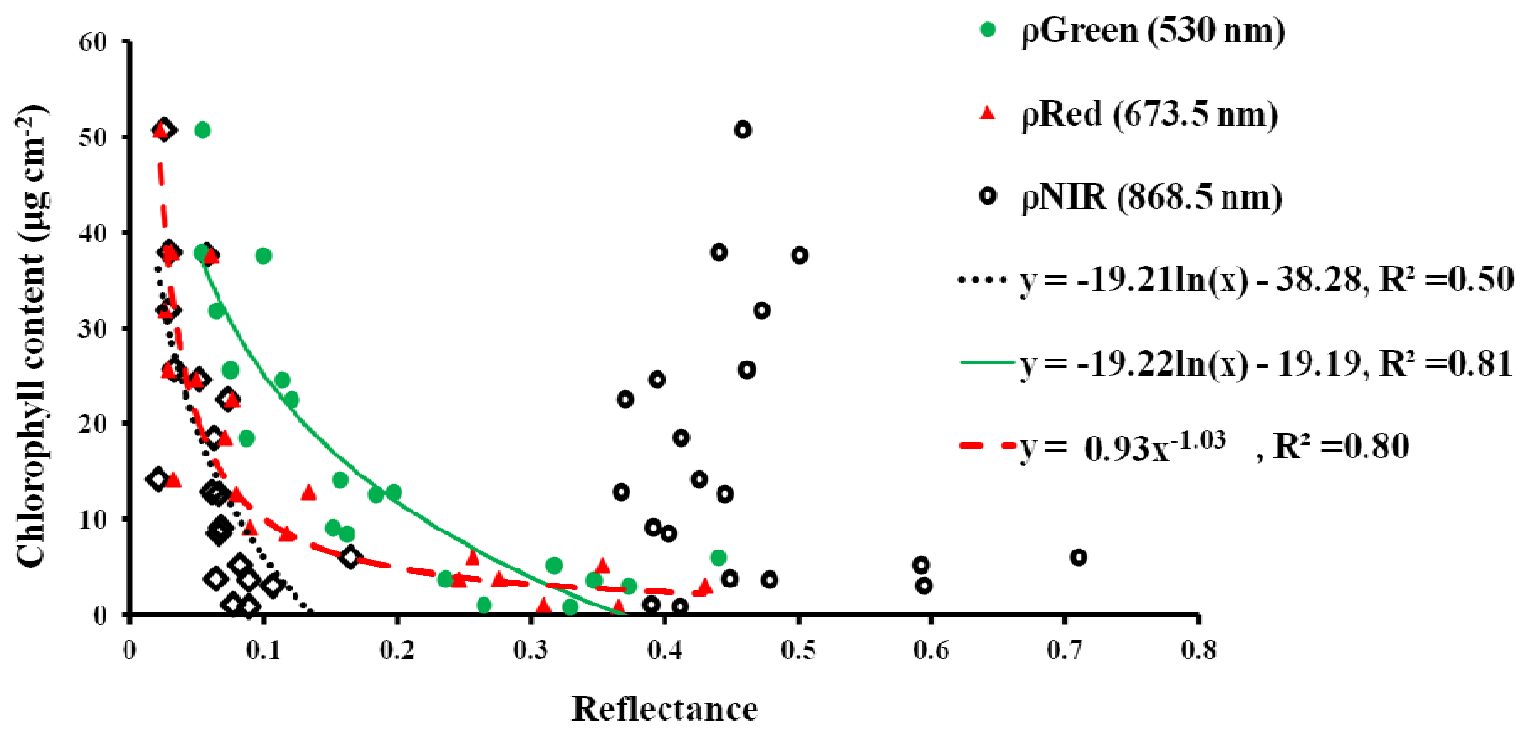


The seven VIs calculated from Equations (2) through (8) are shown in Figure 4. mNDVI and NDVI saturated when chlorophyll content was higher than $10 \mu \mathrm{g} \cdot \mathrm{cm}^{-2}$, and EVI and GNDVI saturated when chlorophyll content was higher than $20 \mu \mathrm{g} \cdot \mathrm{cm}^{-2}$ and $35 \mu \mathrm{g} \cdot \mathrm{cm}^{-2}$, respectively. EVI, NDVI, GNDVI, and SR were strongly positively correlated with chlorophyll content, with coefficients of determination $\left(\mathrm{R}^{2}\right)$ of $0.66,0.68,0.83$, and 0.74 , respectively $(\mathrm{P}<0.001)$. GRVI and mNDVI were more weakly correlated with chlorophyll content, with $\mathrm{R}^{2}$ values of $0.32(\mathrm{P}<0.05)$ and $0.58(\mathrm{P}<0.001)$, respectively. In contrast, $\mathrm{CI}_{\text {green }}$ had the strongest linear correlation with chlorophyll content $\left(\mathrm{R}^{2}=0.87 ; \mathrm{P}<0.001\right)$. Therefore, $\mathrm{CI}_{\text {green, }}$ EVI, NDVI, GNDVI, and SR were selected as candidate VIs for the canopy- and satellite-scale analyses.

Figure 4. The best-fit regression of the linear relationships between (a) green chlorophyll index $\left(\mathrm{CI}_{\text {green }}\right)$, (b) green and red ratio VI (GRVI), (c) enhanced VI (EVI), (d) modified NDVI (mNDVI), (e) NDVI, (f) green NDVI (GNDVI), and (g) simple ratio (SR) index and chlorophyll content $\left(\mu \mathrm{g} \cdot \mathrm{cm}^{-2}\right)$ at the leaf scale.

(a)

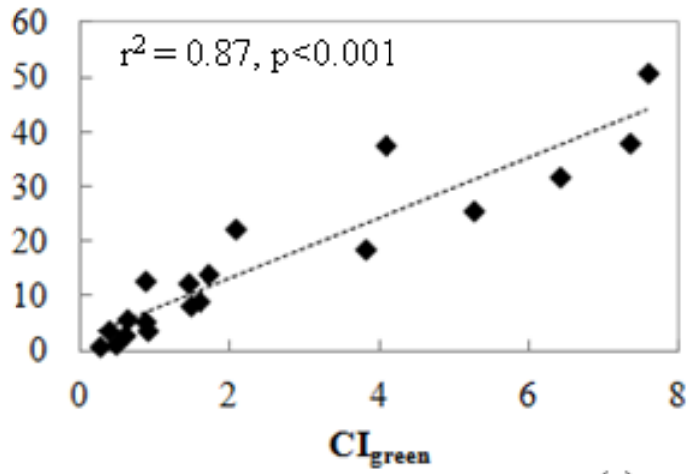

(c)

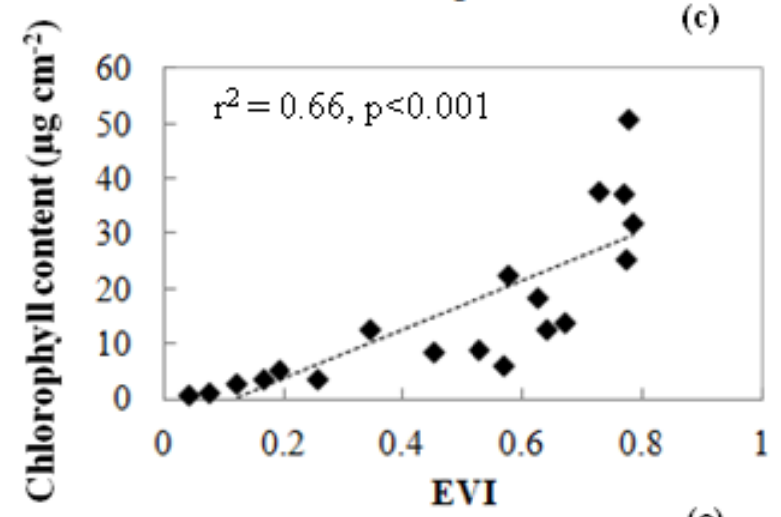

(e)

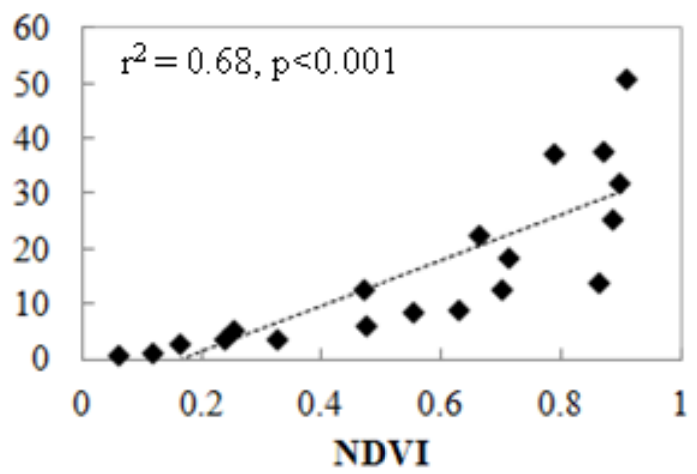

(b)

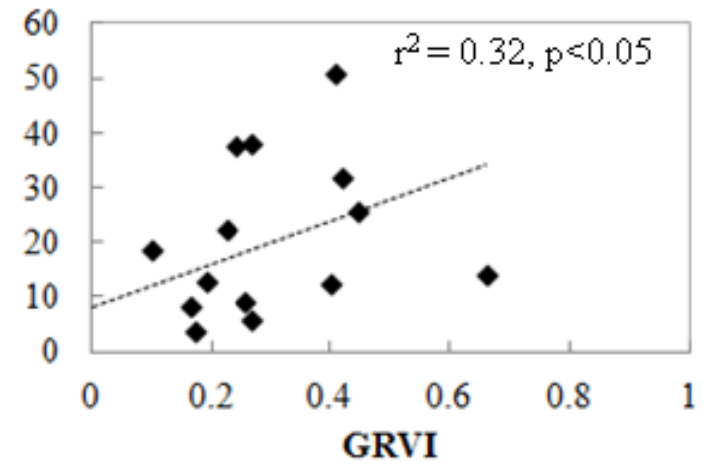

(d)

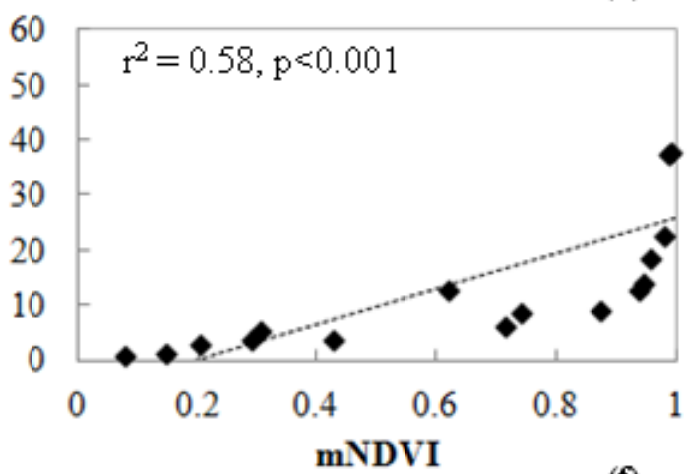

(f)

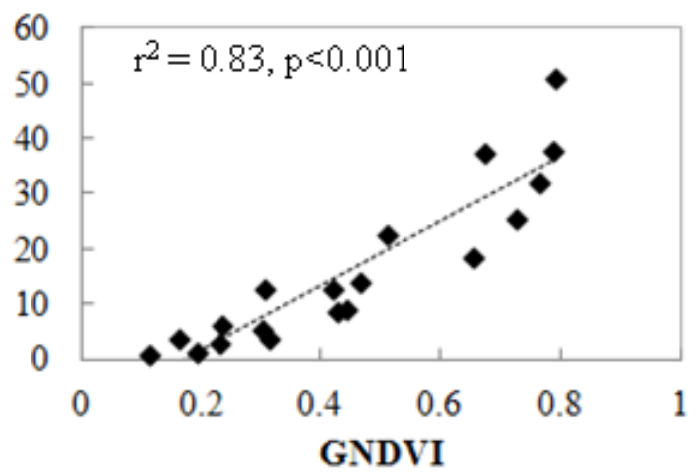


Figure 4. Cont.

(g)

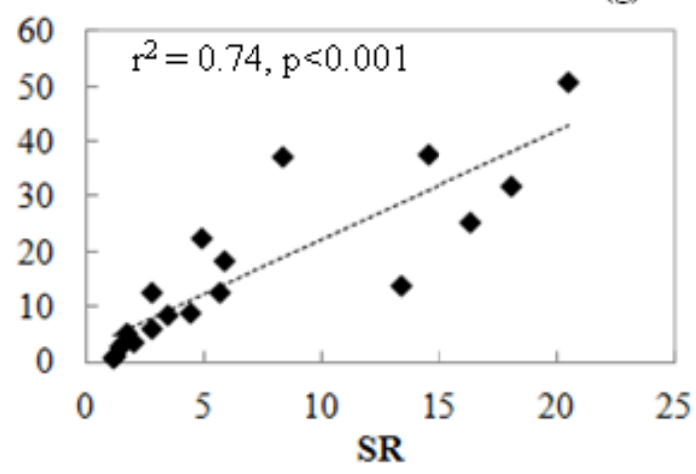

Figure 5. Diurnal variation in the mean half-hourly dataset over 16-day periods: (a) net ecosystem production (NEP), (b) vapor pressure deficit (VPD) at CA-Let, (c) NEP and (d) VPD at TH-SKR, and (e) NEP and (f) VPD at JP-FJY. Arrows indicate the timing of the midday depression.
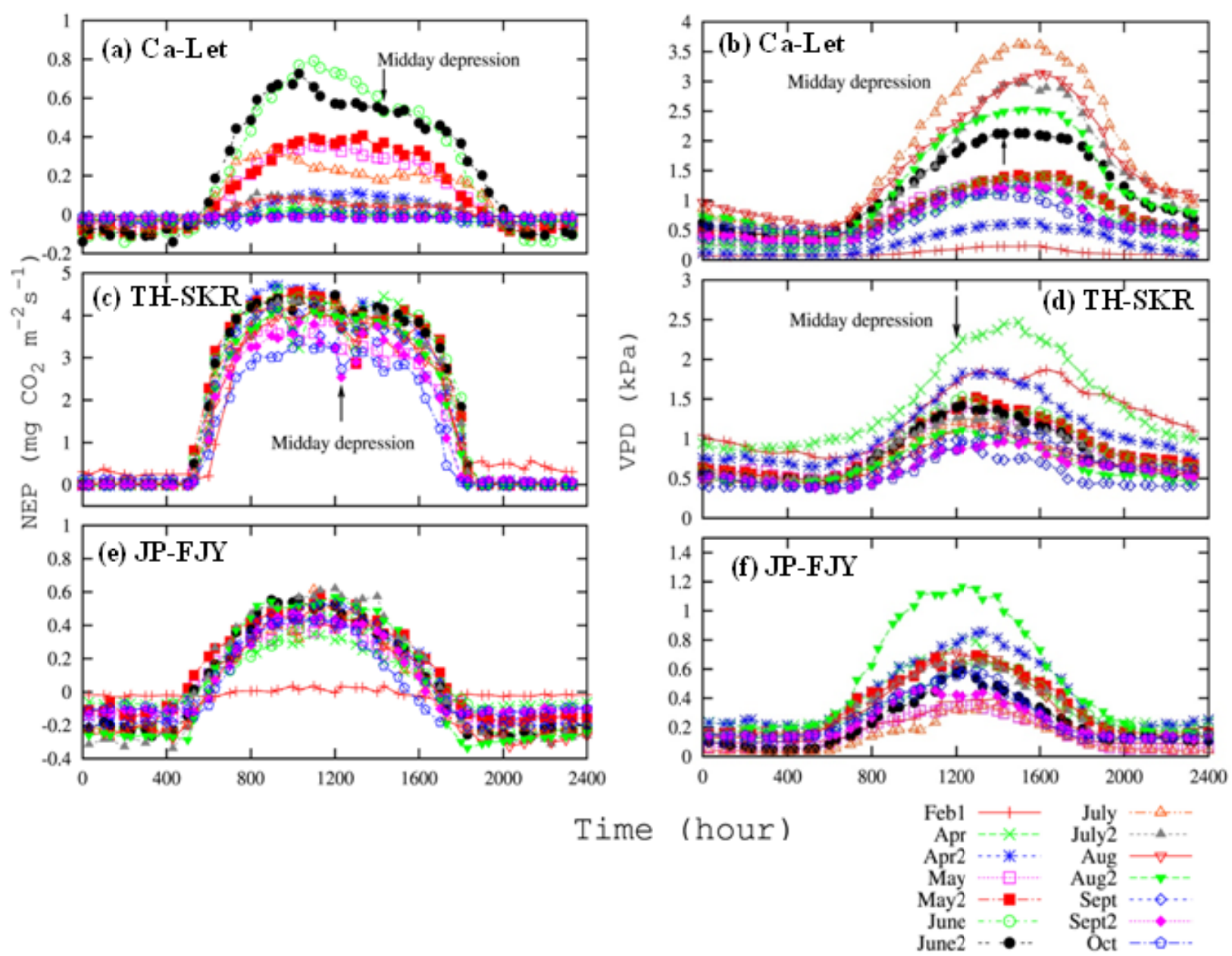

\subsection{GPP capacity Selection Criteria}

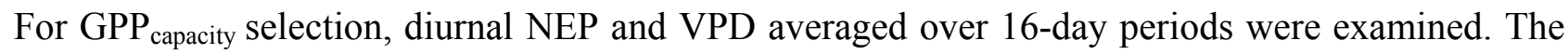
results are shown in Figure 5 for the CA-Let 5(a,b), TH-SKR 5(c,d), and JP-FJY 5(e,f) sites. In Figure 5(a), the midday depression followed Pattern 2 (Figure 2) around 14:00 (local time), as shown 
by the arrow. In Figure 5(b), VPD at the time of the midday depression was around $2 \mathrm{kPa}$, as shown by the arrow. Figure 5(c) shows a midday depression for TH-SKR at around noon, indicating Pattern 2 diurnal variation (Figure 2). In Figure 5(d), VPD at the time of the midday depression was around 2 $\mathrm{kPa}$. VPD values for all Japanese sites were less than $2 \mathrm{kPa}$ (Figure 5(f)). Therefore, daytime GPP $(\mathrm{PAR}>0)$ and VPD $<2 \mathrm{kPa}$ (VPD threshold) were applied as $\mathrm{GPP}_{\text {capacity }}$ selection criteria for each study site.

\subsection{Canopy and Satellite Scales: Results for Broadleaf Deciduous Temperate Trees at JP-TKY}

\subsection{1. $\mathrm{P}_{\text {max }}$ capacity of the Light-Response Curve from EC Flux Data}

To determine $\mathrm{P}_{\text {max }}$ capacity and $\alpha_{\text {slope, }}$, the relationships between GPP capacity $_{\text {and PAR were examined }}$ for broadleaf deciduous temperate trees at JP-TKY in 2003 and 2004, as shown in Figure 6, which

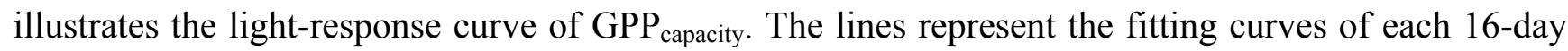
period with $\alpha_{\text {slope }}$ averaged over the growing season. In many cases, the fitted $\mathrm{P}_{\text {max }}$ capacity saturated in regions of unrealistically high PAR, such as $2,500 \mu \mathrm{mol} \cdot \mathrm{m}^{-2} \cdot \mathrm{s}^{-1}$. Thus, we fixed maximum PAR at 2,000 $\mu \mathrm{mol} \cdot \mathrm{m}^{-2} \cdot \mathrm{s}^{-1}$ and defined the maximum GPP capacity when PAR $=2,000 \mu \mathrm{mol} \cdot \mathrm{m}^{-2} \cdot \mathrm{s}^{-1}$ as $\mathrm{P}_{\text {max capacity } 2000 \text {. }}$

Figure 6. Light-response curve of low-stress GPP (GPP capacity) and PAR in broadleaf deciduous temperate trees (JP-TKY) in (a) 2003 and (b) 2004. Lines represent the least-squares fitting curve for each 16-day period. Dots in different colors indicate half-hourly data (no average) of each 16-day period of GPP capacity.

(a) JP-TKY 2003

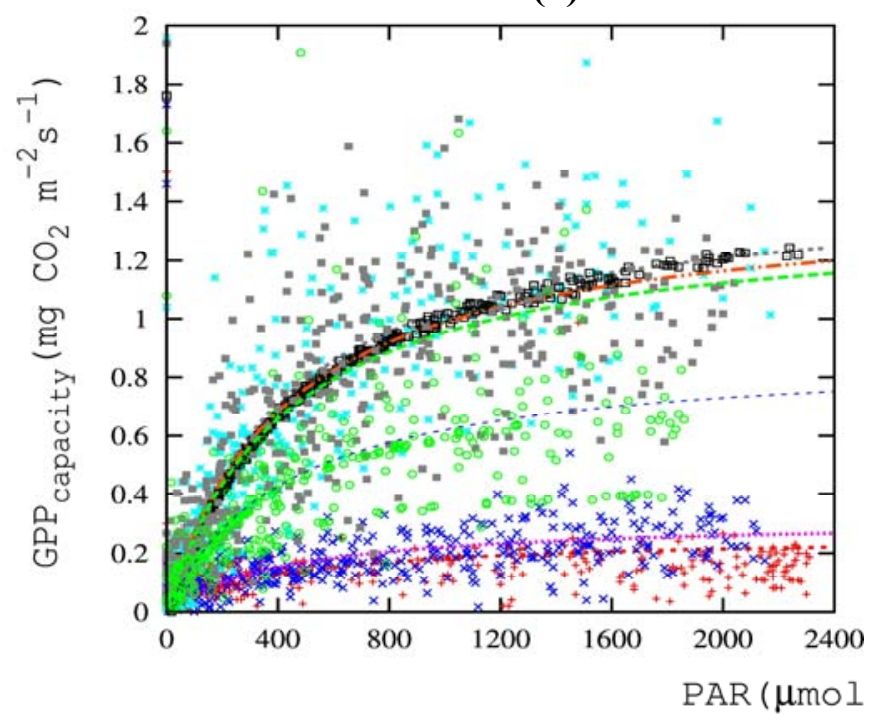

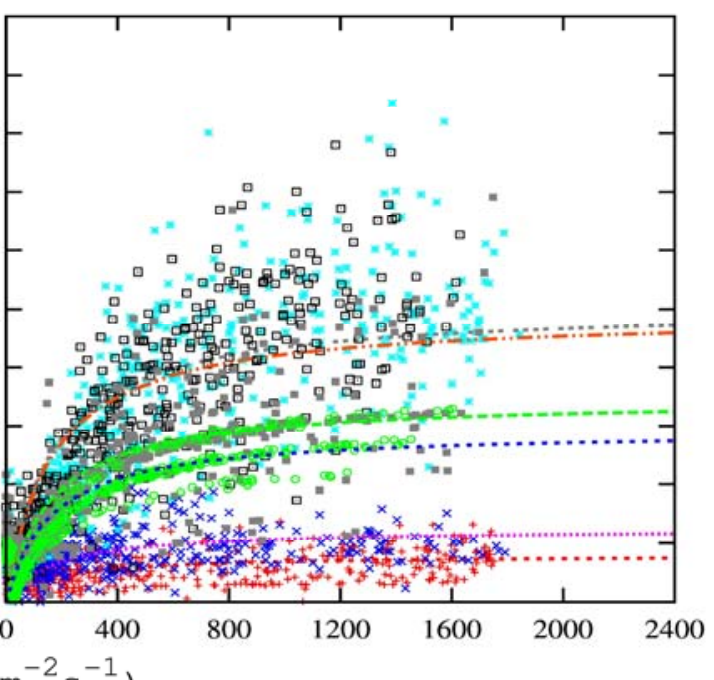

$\left.\mathrm{m}^{-2} \mathrm{~s}^{-1}\right)$

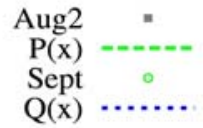

\subsubsection{Relationship of VIs and $\mathrm{P}_{\text {max_capacity } 2000}$}

The relationships between the five candidate VIs ( $\mathrm{CI}_{\text {green, }}$ EVI, NDVI, GNDVI, and SR) and $\mathrm{P}_{\text {max_capacity2000 }}$ at the canopy scale are shown in Figure 7. All five indices exhibited strong correlations 


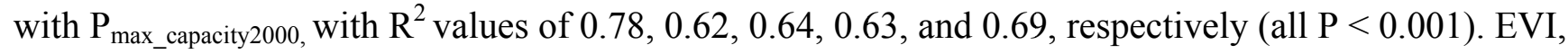
NDVI, GNDVI, and SR became clearly saturated when $\mathrm{P}_{\text {max capacity } 2000}$ was more than about $0.4 \mathrm{mg} \cdot \mathrm{CO}_{2} \cdot \mathrm{m}^{-2} \cdot \mathrm{s}^{-1}$, whereas $\mathrm{CI}_{\text {green }}$ did not saturate. The strongest linear correlation occurred for $\mathrm{CI}_{\text {green. }}$. We obtained the following empirical equation for the relationship between $\mathrm{CI}_{\text {green }}$ and $\mathrm{P}_{\text {max_capacity } 2000}\left(\mathrm{mg} \cdot \mathrm{CO}_{2} \cdot \mathrm{m}^{-2} \cdot \mathrm{s}^{-1}\right): \mathrm{P}_{\text {max_capacity } 2000}=0.13 \times \mathrm{CI}_{\text {green }}-0.13$.

Figure 7. The best fit regression of the linear relationships between various VIs calculated from daily HSSR datasets and $\mathrm{P}_{\text {max }}$ capacity2000 of broadleaf deciduous temperate trees at JP-TKY 2004 at the canopy scale: (a) $\mathrm{CI}_{\text {green }}$, (b) EVI, (c) NDVI, (d) GNDVI, and (e) SR.

(a)
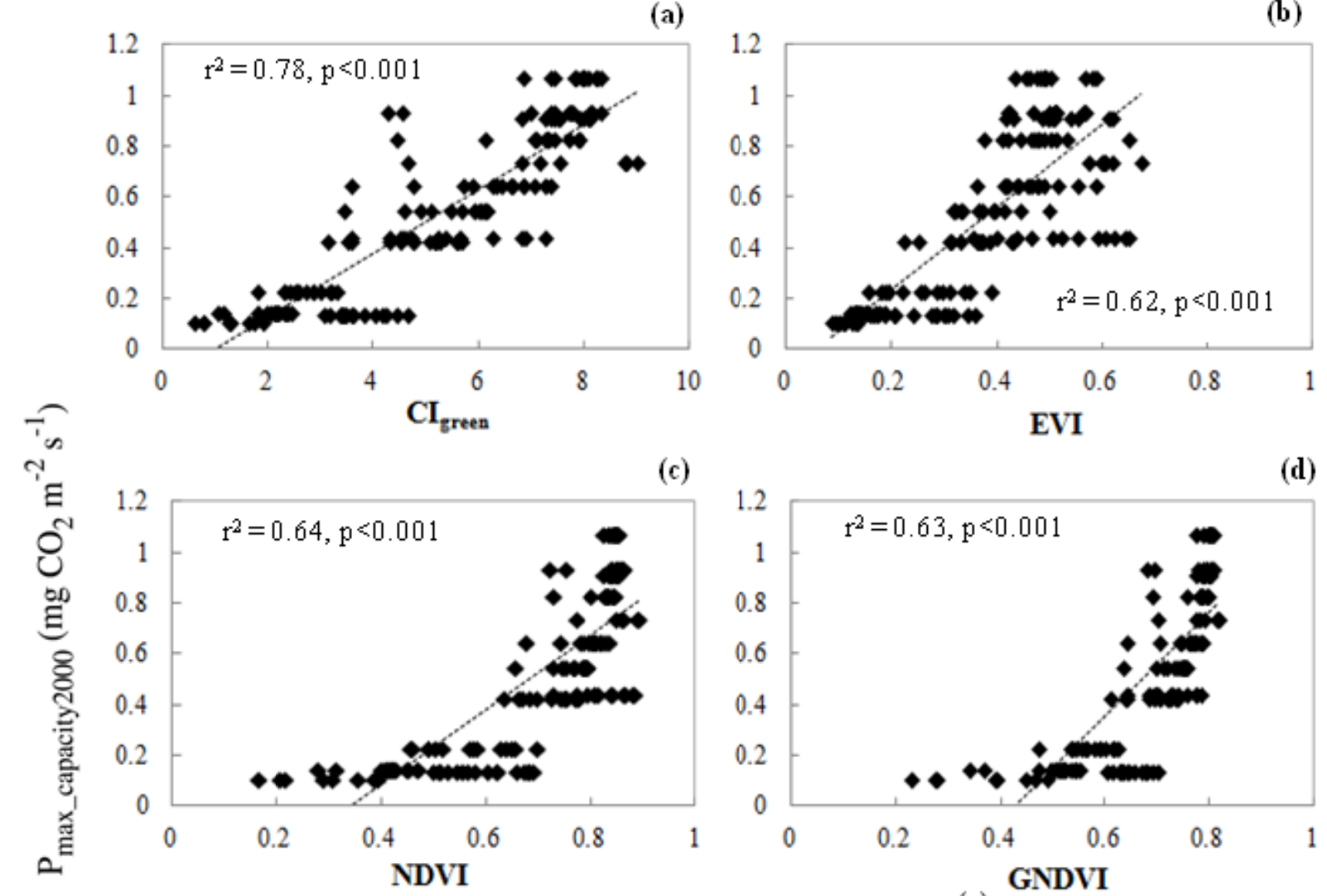

(c)

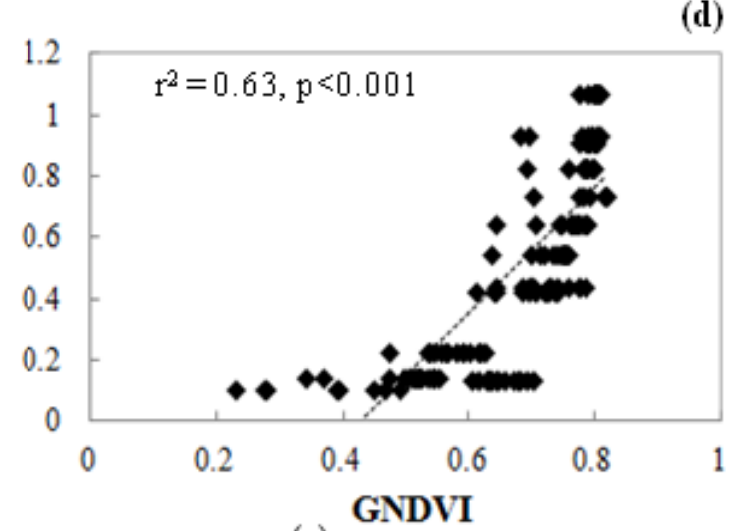

(e)

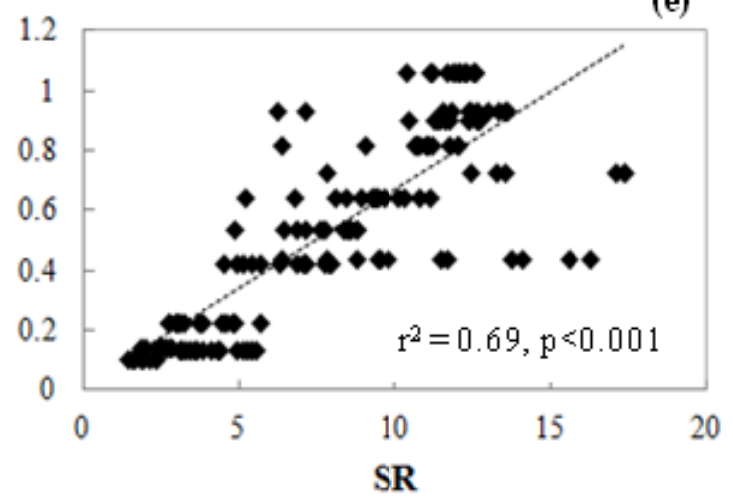

Figure 8 presents the relationships between the five candidate VIs $\left(\mathrm{CI}_{\text {green }}\right.$, EVI, NDVI, GNDVI, and SR) and $\mathrm{P}_{\text {max capacity2000 }}$ at the satellite scale. EVI, NDVI, GNDVI, and SR exhibited strong

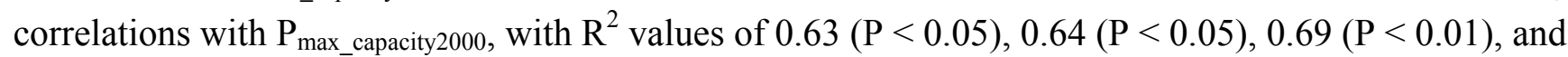
$0.59(\mathrm{P}<0.05)$, respectively. However, the strongest linear correlation occurred for $\mathrm{CI}_{\text {green }}\left(\mathrm{R}^{2}=0.72\right.$, $\mathrm{P}<0.01)$. Thus, compared to EVI, NDVI, GNDVI, and SR, $\mathrm{CI}_{\text {green }}$ was the best VI for estimating 
$\mathrm{P}_{\text {max }}$ capacity2000. We obtained the following empirical equation for the relationship between $\mathrm{CI}_{\text {green }}$ and $\mathrm{P}_{\text {max_capacity2000 }}\left(\mathrm{mg} \cdot \mathrm{CO}_{2} \cdot \mathrm{m}^{-2} \cdot \mathrm{s}^{-1}\right): \mathrm{P}_{\text {max_capacity2000 }}=0.15 \times \mathrm{CI}_{\text {green }}-0.37$.

Figure 8. The best fit regression of the linear relationships between various VIs from 16-day-period MOD09A1 data and $\mathrm{P}_{\text {max capacity2000 of broadleaf deciduous temperate trees at }}$ JP-TKY 2004 at the satellite scale: (a) $\mathrm{CI}_{\text {green, }}$ (b) EVI, (c) NDVI, (d) GNDVI, and (e) SR.

(a)

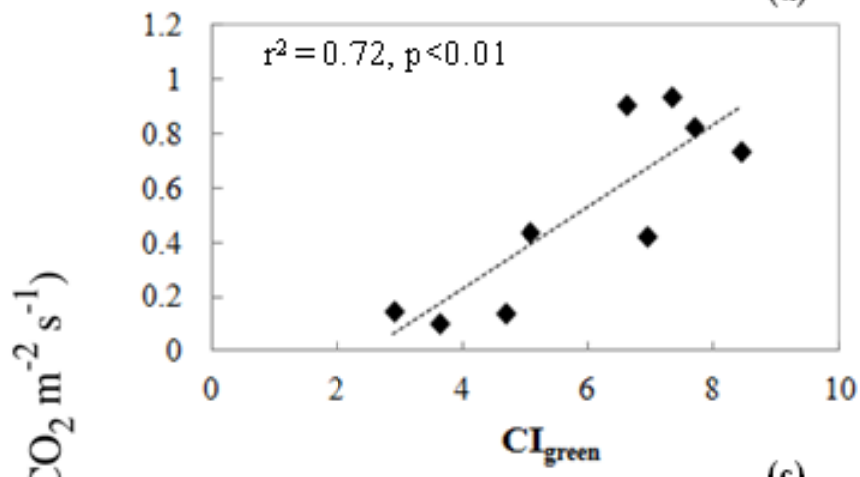

(c)

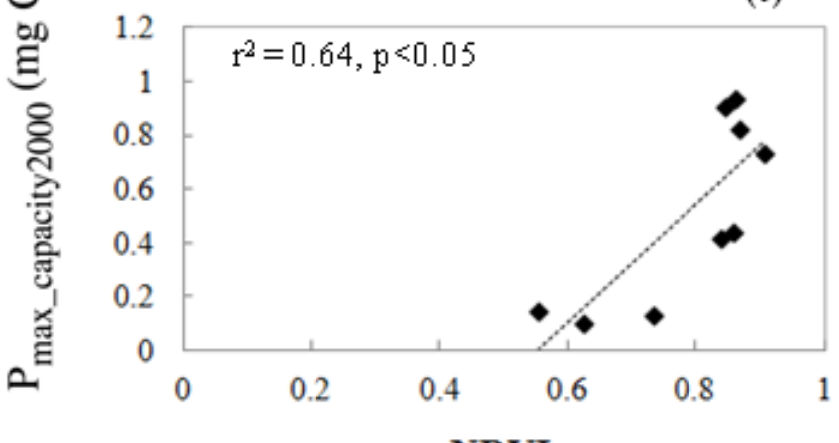

NDVI

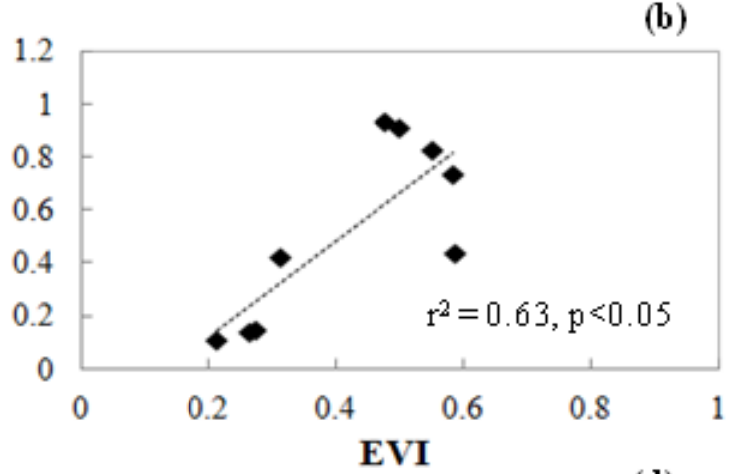

(d)

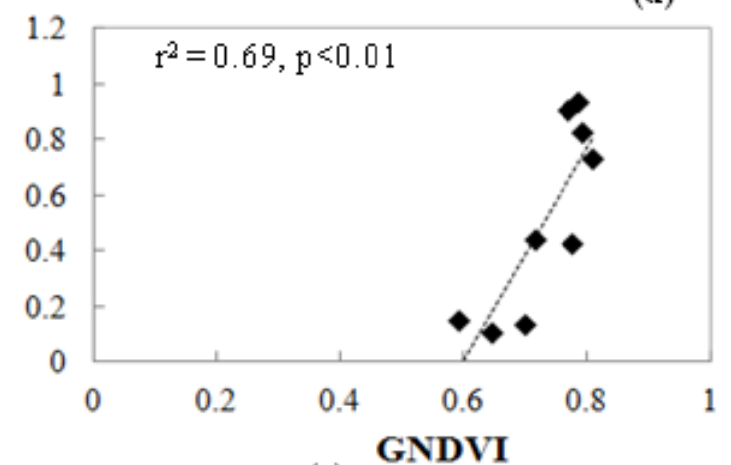

(e)

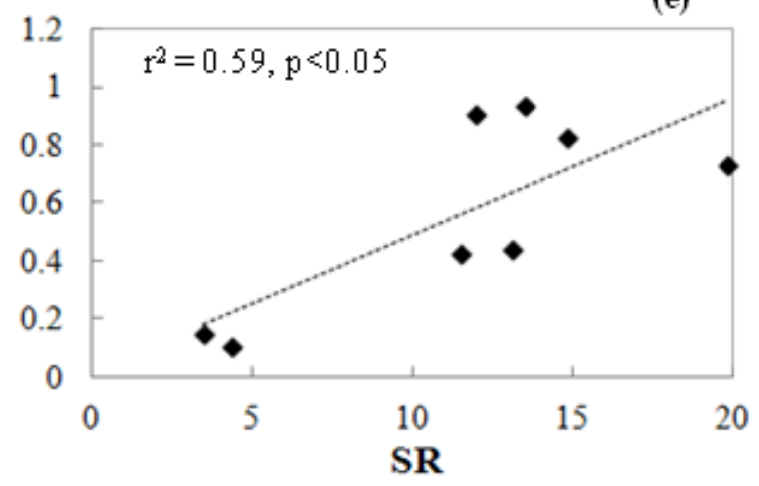

3.4. Satellite-Scale: Results for Various Plant Functional Types

3.4.1. $P_{\text {max_capacity }}$ of the Light-Response Curve from EC Flux Data

The relationships of GPP ${ }_{\text {capacity }}$ and PAR for various plant functional types are shown in Figure 9(a-f), which presents results for C3 grass arctic (CA-Let), needleleaf deciduous trees (JP-TMK), crop-paddy fields (JP-Mase), C3 grass (US-Dk1), needleleaf evergreen temperate trees (JP-FJY), and broadleaf evergreen tropical trees (TH-SKR). The lines are the fitting curves for each 16-day period. The highest rate of photosynthesis occurred in late June at JP-TMK, where the $\mathrm{P}_{\text {max capacity2000 was }}$ 
$1.87 \mathrm{mg} \cdot \mathrm{CO}_{2} \cdot \mathrm{m}^{-2} \cdot \mathrm{s}^{-1}$. Table 3 summarizes the $\mathrm{P}_{\text {max_capacity2000 }}$ and $\alpha_{\text {slope }}$ averaged over the growing season and the VPD thresholds for each of the plant functional types.

Figure 9. The canopy light-response curve of half-hourly data of low-stress GPP $\left(\mathrm{GPP}_{\text {capacity }}\right)$ and PAR for the various plant functional types in 2003: (a) C3 grass, arctic (CA-Let); (b) needleleaf deciduous trees (JP-TMK); (c) paddy fields (JP-Mase); (d) C3 grass (US-Dk1); (e) needleleaf evergreen temperate trees (JP-FJY), and (f) broadleaf evergreen tropical trees (TH-SKR). Lines represent the least-squares fitting curve for each 16-day period. Dots in different colors indicate half-hourly data (no average) of each 16-day period of $\mathrm{GPP}_{\text {capacity. }}$.

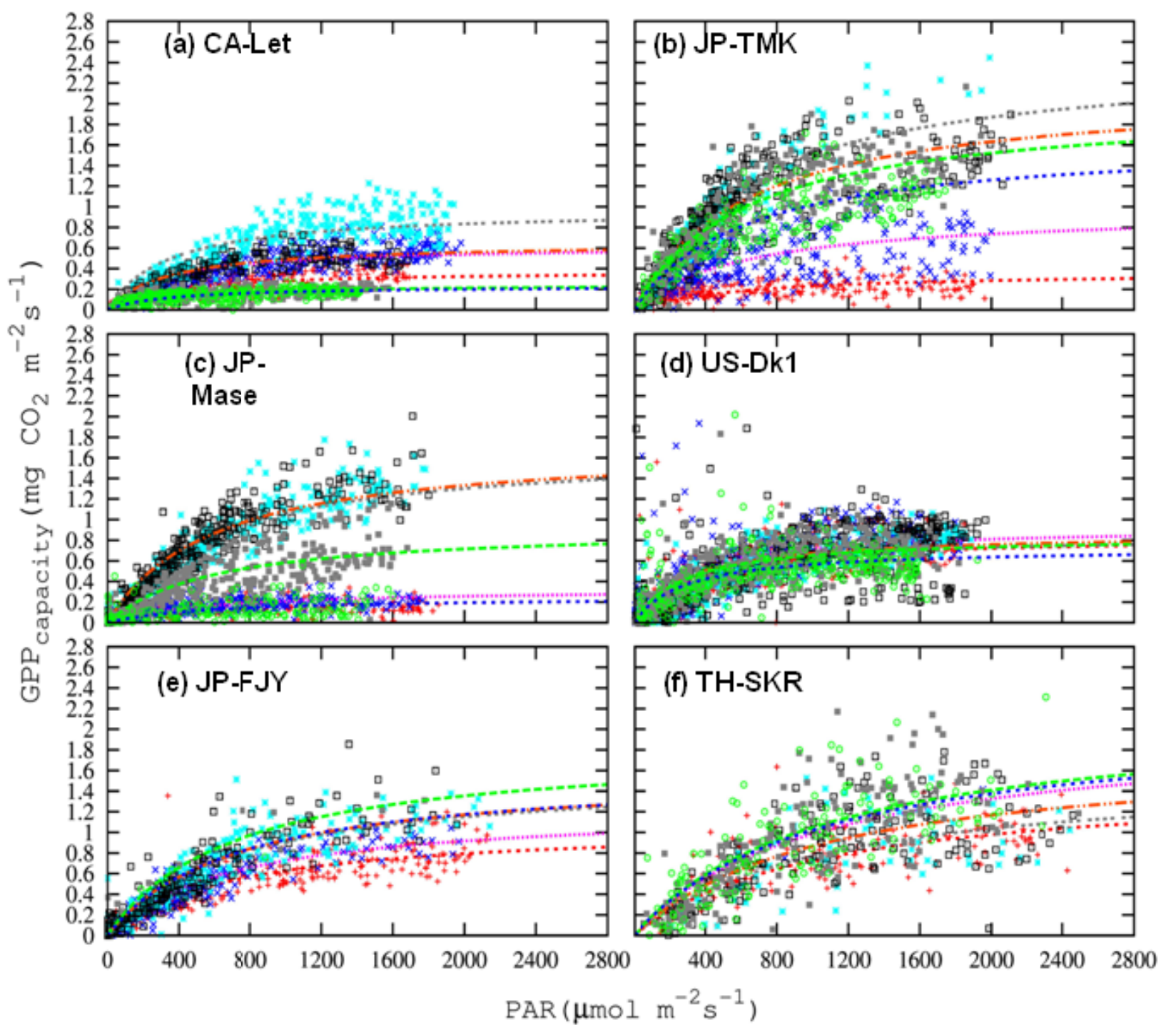

\begin{tabular}{|c|c|c|c|}
\hline Apr2 & + & July & 0 \\
\hline $\mathrm{H}(\mathrm{x})$ & $\cdots \cdots \cdots$ & $M(x)$ & ... \\
\hline May & $x$ & Aug2 & . \\
\hline $\mathrm{I}(\mathrm{x})$ & ...... & $P(x)$ & - \\
\hline $\mathrm{L}(\mathrm{x})$ & ..... & $Q(x)$ & .. \\
\hline
\end{tabular}


Table 3. Summary of the growing season average $P_{\max }$ capacity2000 and initial slope, and the VPD threshold for the seven plant functional types.

\begin{tabular}{|c|c|c|c|c|}
\hline $\begin{array}{l}\text { Site name } \\
\text { (Year 2003) }\end{array}$ & Respiration (Rec) Equation & $\begin{array}{c}\text { VPD } \\
\text { Threshold } \\
\text { (kPa) } \\
\end{array}$ & $\begin{array}{c}{ }^{*} \mathrm{P}_{\text {max_capacity2000 }} \\
\mathrm{mg} \cdot \mathrm{CO}_{2} \cdot \mathrm{m}^{-2} \cdot \mathrm{s}^{-1} \\
(\text { Growing Season) }\end{array}$ & $\begin{array}{c}\text { * Initial slope } \\
\left(\alpha_{\text {slope }}\right)\end{array}$ \\
\hline CA-Let & $\operatorname{Rec}=0.29 \exp \left(0.037 \mathrm{~T}_{\mathrm{air}}\right)$ & 2 & 0.47 (Apr-Sept) & 0.0029 \\
\hline JP-TMK & $\operatorname{Rec}=0.3 \exp \left(0.08 \mathrm{~T}_{\text {soil }}\right)$ & 2 & 1.37 (May-Oct) & 0.0016 \\
\hline JP-TKY & $\operatorname{Rec}=0.23 \times 0.23 \exp \left(0.08 \mathrm{~T}_{\mathrm{air}}\right)$ & 2 & 0.97 (May-Sept) & 0.0023 \\
\hline JP-Mase & $\operatorname{Rec}=0.18 \exp \left(0.067 \mathrm{~T}_{\mathrm{air}}\right)$ & 2 & 0.96 (May-Aug2) & 0.0017 \\
\hline JP-FJY & $\mathrm{Rec}=0.25 \times 0.25 \exp \left(0.08 \mathrm{~T}_{\mathrm{air}}\right)$ & 2 & $1.00(\mathrm{Apr}-\mathrm{Oct})$ & 0.0014 \\
\hline US-Dk1 & $-* *$ & 2 & $0.70(\mathrm{Apr}-\mathrm{Oct})$ & 0.0035 \\
\hline TH-SKR & $\begin{array}{l}\operatorname{Rec}= \\
0.025 \times 2.57 \exp \left(\left(\mathrm{T}_{\text {air }}-10\right) / 10\right)\end{array}$ & 2 & $\begin{array}{l}1.18 \text { (Apr-Oct, } \\
\text { except May2 and } \\
\text { June) }\end{array}$ & 0.0009 \\
\hline
\end{tabular}

* Averaged values (averaged over growing season), $\mathrm{T}_{\text {soil }}=$ Soil temperature, $\mathrm{T}_{\text {air }}=$ Air temperature, $\mathrm{VPD}=$ Vapor Pressure Deficit; ** Rec was not calculated because AmeriFlux provided GPP for this site.

\subsubsection{Relationships of $\mathrm{CI}_{\text {green }}$ and $\mathrm{P}_{\text {max_capacity } 2000}$}

Figure 10 presents the linear relationships between $\mathrm{CI}_{\text {green }}$ and $\mathrm{P}_{\text {max }}$ capacity2000 for the seven plant functional types. For CA-Let, JP-TMK, JP-TKY, JP-Mase, and JP-FJY, the $\mathrm{R}^{2}$ values of the $\mathrm{CI}_{\text {green }}-\mathrm{P}_{\text {max_capacity2000 }}$ correlations were $0.81,0.84,0.67,0.95$, and 0.70 , respectively. A linear correlation was not found for TH-SKR, as $\mathrm{CI}_{\text {green }}$ and $\mathrm{P}_{\text {max }}$ capacity2000 changed very little. Additionally, a linear correlation was not observed for US-Dk1. The linear regression functions $(y=\mathrm{ax} \pm \mathrm{b})$ for CA-Let, JP-TMK, JP-TKY, JP-Mase, and JP-FJY are summarized in Table 4. Differences in these empirical equations reveal the characteristics of each plant functional type.

Figure 10. Relationships between $\mathrm{CI}_{\text {green }}$ calculated from 16-day period MOD09A1 data and $\mathrm{P}_{\text {max capacity2000 }}$ and maximum light-use efficiency (LUE $\mathrm{max}_{\text {man }}$ ) for the seven plant functional types in 2003.

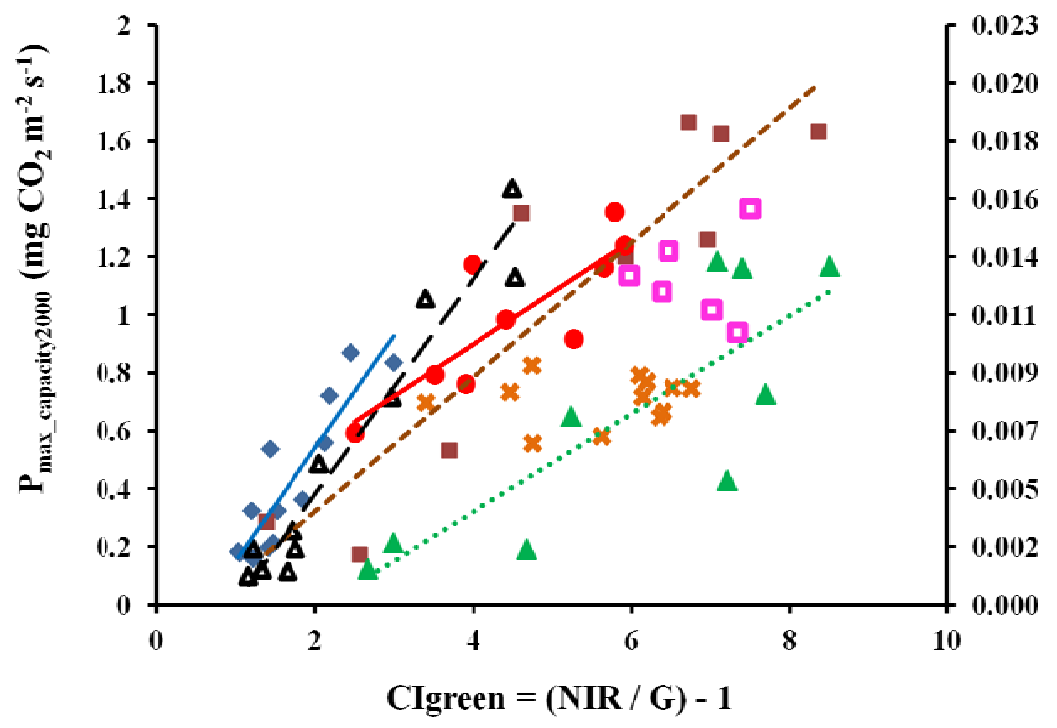

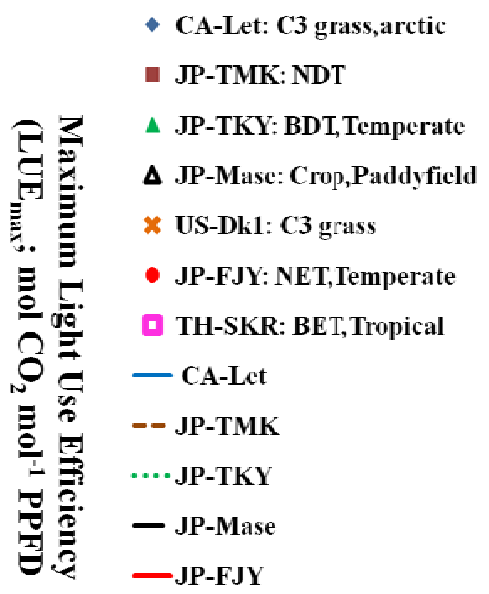


Table 4. Coefficients, intercepts and correlation coefficients $\left(\mathrm{R}^{2}\right)$ of the linear correlations $(y=\mathrm{a} x \pm \mathrm{b})$ between $\mathrm{CI}_{\text {green }}$ and $\mathrm{P}_{\text {max_capacity2000 }}$ for CA-Let, JP-TMK, JP-TKY, JP-Mase, and JP-FJY.

\begin{tabular}{llccc}
\hline Site Name & Plant Functional Types (PFTs) & $\mathbf{a}$ & $\mathbf{b}$ & $\mathbf{R}^{\mathbf{2}}$ \\
\hline CA-Let & C3 grass, arctic & 0.388 & -0.235 & 0.81 \\
JP-TMK & Needleleaf deciduous trees (NDT) & 0.232 & -0.145 & 0.84 \\
JP-TKY & Broadleaf deciduous trees, temperate (BDT, temperate) & 0.169 & -0.355 & 0.67 \\
JP-Mase & Crops (paddy field) & 0.371 & -0.361 & 0.95 \\
JP-FJY & Needleleaf evergreen trees, temperate (NET, temperate) & 0.179 & 0.182 & 0.70 \\
\hline
\end{tabular}

Figure 11. Comparison of estimated $P_{\text {max capacity2000 (black line) and observed }}$ $P_{\text {max capacity2000 }}$ (red line) with error bars. (a) CA-Let 2002, (b) JP-TMK 2002, (c) JP-TKY 2004, (d) JP-Mase 2002, (e) JP-FJY 2004, and (f) TH-SKR 2002. Estimated P $P_{\text {max_capacity2000 }}$ calculated using empirical linear correlation of 2003 and $\mathrm{CI}_{\text {green }}$ of 2002 and 2004. Observed $\mathrm{P}_{\text {max capacity2000 }}$ estimated from EC flux tower data of 2002 and 2004 using light-response curve fitting by the least-squares method.
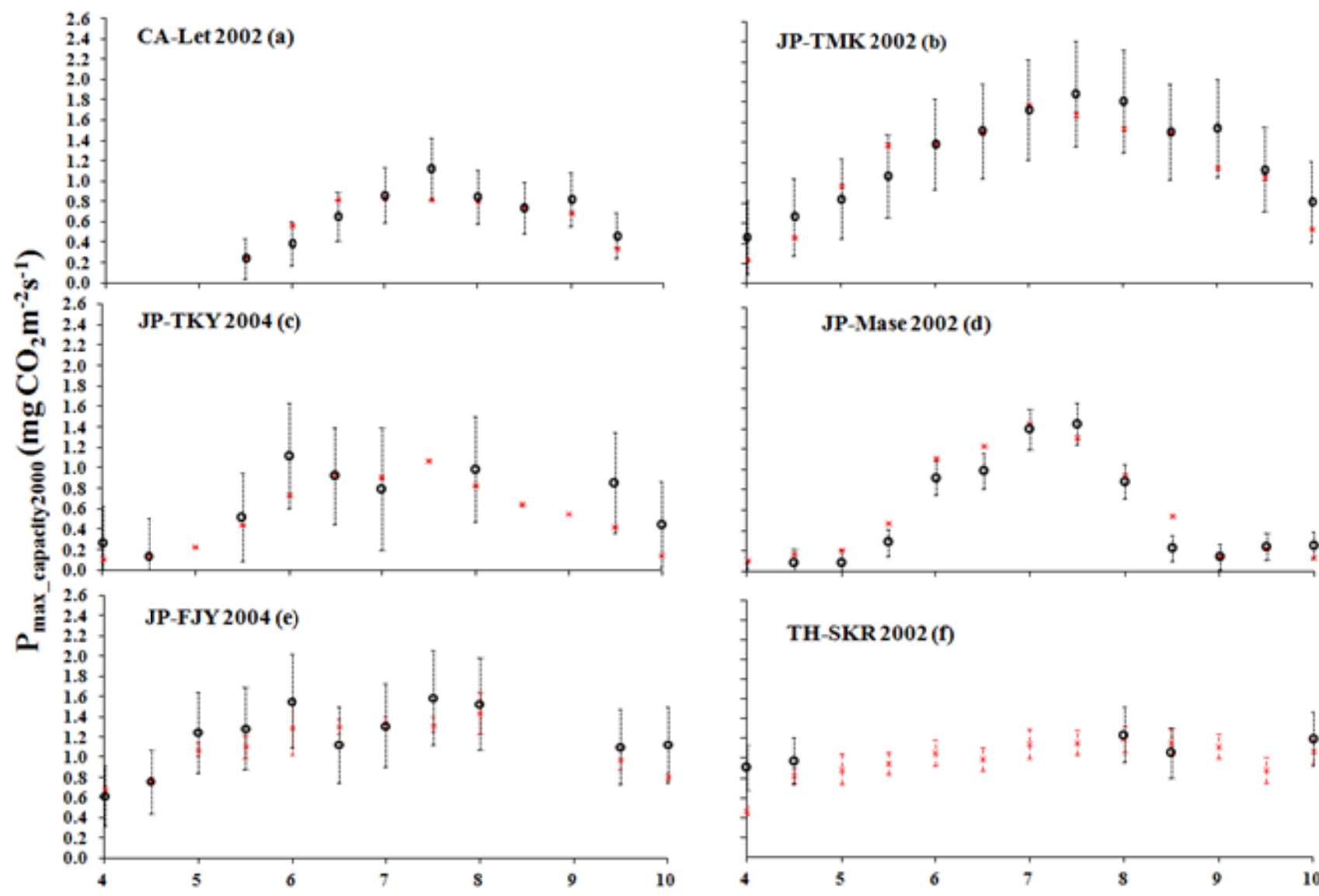

TH-SKR 2002 (1)

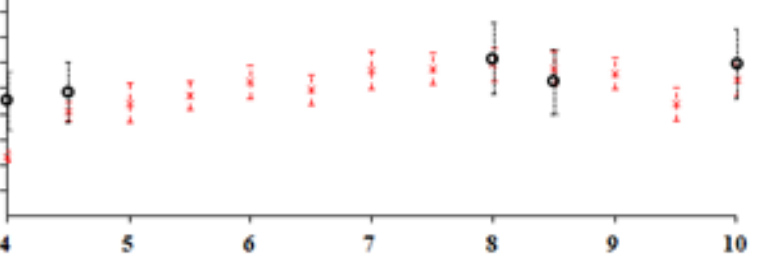

Month

× Observed $\circ$ Estimated

\subsubsection{Validation of $\mathrm{CI}_{\text {green }}$}

To test the potential of $\mathrm{CI}_{\text {green }}$ to estimate $\mathrm{P}_{\text {max }}$ capacity2000 in a different year, we used the empirical equations of year 2003 (Table 4) and $\mathrm{CI}_{\text {green }}$ calculated from MOD09A1 for the CA-Let, JP-TMK, 
JP-Mase, and TH-SKR sites in 2002 and the JP-TKY and JP-FJY sites in 2004. Comparisons of estimated $\mathrm{P}_{\text {max }}$ capacity2000 and observed $\mathrm{P}_{\text {max }}$ capacity2000 with standard error bars are shown in Figure 11. Estimated $\mathrm{P}_{\text {max }}$ capacity2000 was obtained from the empirical equations in Table 4, and observed $\mathrm{P}_{\text {max }}$ capacity2000 was calculated from the flux data. Standard errors of estimated $\mathrm{P}_{\text {max_capacity2000 }}$ were calculated from standard-error propagation of empirical relationships between $\mathrm{CI}_{\text {green }}$ and

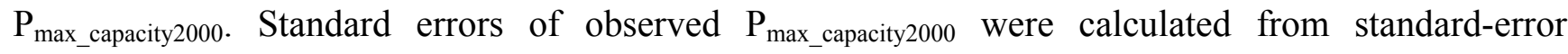
propagation of least-square fitting of the light-response curves. The standard errors of the estimated $\mathrm{P}_{\text {max_capacity2000 }}$ from linear regression were larger than those of observed $\mathrm{P}_{\text {max capacity2000. Figure } 11}$ shows that the observed $\mathrm{P}_{\text {max }}$ capacity2000 values for all plant functional types were within the standard error of the estimated $\mathrm{P}_{\text {max }}$ capacity2000, especially in spring, when most of the plant functional types showed better matching. These results indicate that the $\mathrm{CI}_{\text {green }}$ and empirical equations successfully estimated $\mathrm{P}_{\text {max }}$ capacity2000 for all plant functional types. For TH-SKR, only five periods are shown because most $\mathrm{CI}_{\text {green }}$ data were affected by clouds.

\section{Discussion}

At the leaf scale, the results show that $\mathrm{CI}_{\text {green }}$ has a strong correlation with variation in leaf chlorophyll content from a wide range of species and leaf development stages (Figure 4). This result agrees with that of Gitelson et al. [50], who demonstrated a wide range of leaf greenness and found that the maximum sensitivity of the reflectance coincides with green absorption. The green wavelength range was also reported to be superior for determining chlorophyll content in eight crops [69]. VI based on red reflectance $(680 \mathrm{~nm})$ was largely insensitive to variation in chlorophyll content. For most leaves, when light enters the upper surface of a leaf, blue light and red light are absorbed by chloroplasts near the irradiated surface, owing to strong absorption bands of chlorophyll in the blue and red regions of the spectrum. Because blue overlaps with the absorption of carotenoids, it is not generally used for estimation of chlorophyll content [57]. The green band wavelength of SGLI ranges from 520 to $540 \mathrm{~nm}$, and the spectral reflectance around $520 \mathrm{~nm}$ is determined not only by chlorophyll-a and chlorophyll-b absorption, but also by carotenoid absorption [24]. However, the pigments contributing most to light absorption in the PAR region are those that are intimately involved in photosynthesis, namely, chlorophyll $\mathrm{a}$ and $\mathrm{b}$ and carotenoids [70]. Moreover, during the growing season as the chlorophyll content in leaves increases, the spectral features of carotenoids diminish owing to the strong and overlapping absorption by chlorophyll [71]. Therefore, the green band of SGLI can serve as a good representative wavelength for estimating leaf chlorophyll content.

Because leaf chlorophyll content increases toward the middle of a leaf [48] and because green light penetrates deeper into the leaf, green reflected light is decreased by chlorophyll content absorption. Thus, green reflected light is very effective for detecting chlorophyll content and can represent leaf photosynthesis. To select an appropriate VI for estimating chlorophyll content, we chose $\mathrm{CI}_{\text {green }}$ because NIR is insensitive to chlorophyll content and the ratio between the insensitive and sensitive bands can minimize the variations in leaf-scattering properties [72]. Furthermore, the reflectance of NIR and green wavelengths has a strong linear correlation with chlorophyll content [72-74]. Therefore, $\mathrm{CI}_{\text {green }}$ is suitable for estimating leaf chlorophyll content. 
Yoder and Waring [75] found that the chlorophyll concentration of sun-exposed canopy was closely related to both leaf and canopy photosynthetic capacity in a Douglas fir canopy in a controlled environment. The correlation coefficient for sun-exposed canopy was higher than that for shaded canopy. Moreover, the NDVI calculated using a narrow green band $(565-575 \mathrm{~nm})$ was best correlated with photosynthesis potential under sunlight. Thus, it is possible to estimate the photosynthetic capacity of a sun-exposed canopy by integrating the leaf photosynthetic capacity.

At the canopy and satellite scales, $\mathrm{P}_{\text {max }}$ capacity2000 was used instead of the canopy chlorophyll content because chlorophyll content within a vegetation canopy is positively related to the productivity of that vegetation [31]. To obtain $\mathrm{P}_{\text {max_capacity }}$ from the light-response curve, some researchers have applied a non-rectangular hyperbolic equation $[46,76-78]$ with three main parameters: initial slope, $\mathrm{P}_{\max }$, and convexity. A non-rectangular hyperbola yielded a better fit than a rectangular hyperbola equation with only two parameters (initial slope and $\mathrm{P}_{\max }$ ). However, we chose to use a rectangular hyperbola (Equation (1)) to obtain $\mathrm{P}_{\text {max } \_ \text {capacity }}$ with constant $\alpha_{\text {slope }}$ to simplify the methodology and minimize the number of parameters [79-82]. Our results demonstrate the applicability of the rectangular hyperbola using constant $\alpha_{\text {slope }}$ for calculating $\mathrm{P}_{\text {max }}$ capacity2000 for each plant functional type.

To estimate GPP at the global scale, we prefer the VI which has linear relation with chlorophyll

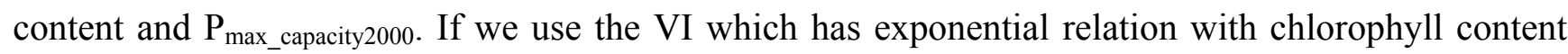
and $\mathrm{P}_{\text {max }}$ capacity2000, it may cause big error in high chlorophyll content or $\mathrm{P}_{\text {max_capacity2000 }}$ region. In big VI region, and with exponential form VI, small error of VI makes big error of chlorophyll content and

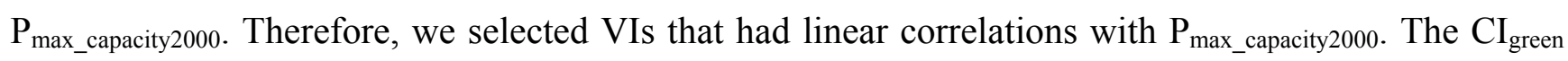
showed a strong linear correlation $\left(\mathrm{R}^{2}>0.67\right)$ with $\mathrm{P}_{\text {max_capacity2000 }}$ for each of the plant functional types and did not have saturation problems in various plant-canopy structures. Linear correlations between remote sensing-obtained VI values and GPP from local flux measurements were found in North American vegetation [83], evergreen needle leaf forests [84], deciduous broadleaf forests [85], and Amazon rainforests [86]. However, these studies did not use GPP in low-stress conditions and the linear regressions showed some scattered data [51].

In Figure 10, linear correlations were observed at every site except US-Dk1 and TH-SKR. US-Dk1 has a spatial resolution problem with MOD09. US-Dk1 covers approximately $480 \times 305 \mathrm{~m}$, which is less than the MOD09 $1-\mathrm{km}$ spatial resolution [87]. Furthermore, the $\mathrm{CI}_{\text {green }}$ range of $3.5-6.5$ is relatively high for grassland, suggesting contamination by light reflected from surrounding evergreen and deciduous forests. Similarly, linear correlations were not found at TH-SKR, where $\mathrm{CI}_{\text {green }}$ and large photosynthetic capacity changed less year-round. These results indicate that when canopy greenness is stable, other meteorological factors will play limiting roles for GPP [42]. The maximum and minimum of $\mathrm{P}_{\text {max_capacity2000 }}$ at TH-SKR in 2003 were 1.37 and $0.94 \mathrm{mg} \cdot \mathrm{CO}_{2} \cdot \mathrm{m}^{-2} \cdot \mathrm{s}^{-1}$, respectively. These results are consistent with those of Aguilos et al. [88], who reported that maximum and minimum values of the saturation point of photosynthesis $\left(\mathrm{GPP}_{\max }\right)$ at TH-SKR in 2003 were 1.54 and $0.82 \mathrm{mg} \cdot \mathrm{CO}_{2} \cdot \mathrm{m}^{-2} \cdot \mathrm{s}^{-1}$, respectively. Tropical forests have the least seasonality in terms of carbon absorption, emission, and greenness [89]. JP-FJY is generally classified as a needleleaf evergreen forest, but seasonal changes in leaves occur. Our results agree with those of Ohtani et al. [90], who found that the seasonal change in LAI at JP-FJY ranged from 3 to 5. Needle-fall and expansion mainly occurred in November and May, respectively. The LAI increased rapidly in early May, reached a maximum in midsummer, and then decreased from September to November. Moreover, for further 
global GPP estimation, we may use the same empirical linear equation for evergreen forest sites JP-

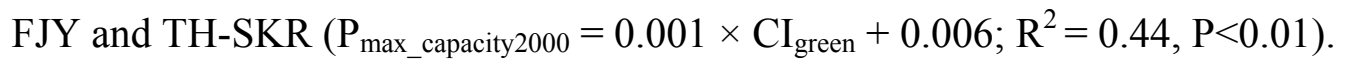

$\mathrm{P}_{\text {max capacity2000 }}$ can be converted to the maximum incident LUE (GPP/PAR) as shown in Figure 10. Observed CI represents different growth states and is related to seasonal changes of incident LUE in a similar manner as for wheat [38]. This method has good potential for estimating seasonal changes of maximum incident $\mathrm{LUE}$ from $\mathrm{CI}_{\text {green }}$.

Our $\mathrm{P}_{\text {max capacity2000 }}$ estimation concept is more similar to the greenness and radiation (GR) model $[37,39,42]$ than to the LUE model. However, the framework for the estimation of GPP capacity differs from those of both the GR and LUE models. The GR and LUE models assume a linear relationship between GPP and incident PAR or PAR during an integral time such as 1 day or 1 month. Our GPP capacity estimation framework introduced a non-linear relationship between photosynthesis velocity and PAR. $\mathrm{P}_{\text {max }}$ capacity was the parameter of the photosynthesis response curve (Equation (1)) and was estimated from $\mathrm{CI}_{\text {green }}$. Using this parameter, the photosynthesis response curve was

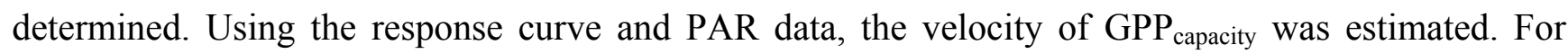
calculation of GPP during a particular time frame, integration of the velocity of GPP capacity is required. Our GPP capacity estimation framework is the differential form.

Moreover, our approach coincides with that of Gitelson et al. [41], who discussed that uncertainty in their crop GPP estimation model (GPP $\propto$ VI $\left.\times \mathrm{PAR}_{\text {potential }}\right)$ arose because of its failure to detect variation in GPP related to short-term (minutes to hours) changes in controlling factors that do not immediately affect crop chlorophyll content. And Hashimoto et al. [91] discussed that although annual mean LAI correlates well with annual GPP, seasonal LAI correlates poorly with seasonal GPP because it does not respond to short term stresses such as anomalous heat waves. Therefore, our approach using a VI to estimate GPP under the low-stress condition (GPP capacity $)$ is quite efficient.

In the present study, we applied a VI to estimate canopy chlorophyll content of the effective leaf area exposed to light. The next step is to refine the effective leaf area by incorporating plant structural characteristics, such as leaf angle orientation and sunlit/shaded leaf and foliar clumping, which are important to GPP estimation because they affect light interception by leaves and light penetration into the canopy $[16,17,92]$ and produce bidirectional reflectance effects in the canopy. In future studies, variation in the slope of the linear correlation between $\mathrm{CI}_{\text {green }}$ and $\mathrm{P}_{\text {max_capacity2000 }}$ for each plant functional type should be compared with results from a radiative transfer model that can predict the radiative transfer of solar energy or changes in leaf physiology as canopy profiles adapt to sunlight [75].

\section{Conclusion}

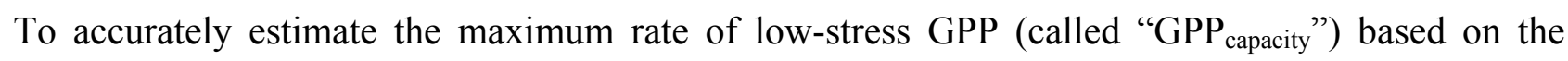
light-response curve, an appropriate VI was selected. The green chlorophyll index, $\mathrm{CI}_{\text {green }}\left(\rho_{\mathrm{NIR}} / \rho_{\text {green }}-1\right)$, had a strong linear correlation with chlorophyll content at the leaf scale and with $\mathrm{GPP}_{\text {capacity }}$ at the canopy and satellite scales. We demonstrated that $\mathrm{CI}_{\text {green }}$ could capture seasonal changes and variation in photosynthesis patterns in six main plant functional types. Therefore, we consider $\mathrm{CI}_{\text {green }}$ to be

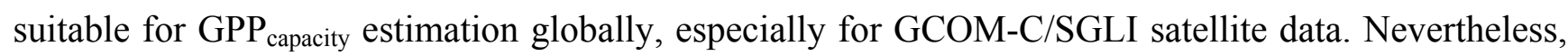
$\mathrm{CI}_{\text {green }}$ should be validated further in different areas and with other plant functional types [93] to test its robustness and sensitivity over a global range of vegetation conditions. 


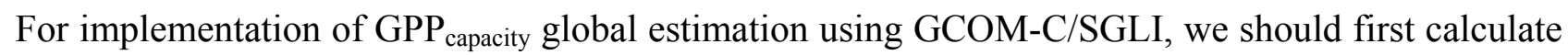
$\mathrm{CI}_{\text {green }}$ from satellite data and use the empirical linear equation from Table 4 to estimate the

$\mathrm{P}_{\text {max } \_ \text {capacity2000 }}$ (the maximum $\mathrm{GPP}_{\text {capacity }}$ when $\mathrm{PAR}=2,000 \mu \mathrm{mol} \cdot \mathrm{m}^{-2} \cdot \mathrm{s}^{-1}$ ). The $\mathrm{P}_{\text {max }}$ capacity (the maximum GPP ${ }_{\text {capacity }}$ under light saturation) in Equation (1) should be calculated using $\mathrm{P}_{\text {max }}$ capacity2000, PAR of $2,000 \mu \mathrm{mol} \cdot \mathrm{m}^{-2} \cdot \mathrm{s}^{-1}$ and $\alpha_{\text {slope }}$ (photosynthetic quantum efficiency) in Table 3 for each plant functional type. Then, GPP capacity should be estimated with the PAR obtained by satellite using Equation (1).

Additionally, in the future, the global GPP capacity can be combined with vegetation stress maps to estimate global GPP. Stress maps may be calculated from environmental conditions such as the vapor pressure deficit, leaf water potential, and soil water content. We expect that our approach will be useful for improving the accuracy of global GPP estimations derived from satellite data.

\section{Acknowledgements}

This research was partly supported by a Global Change Observation Mission (GCOM; PI\#102 and 106) of the Japan Aerospace Exploration Agency (JAXA). We acknowledge JAXA for GLI data, the Land Processes (LP) DAAC for MODIS datasets and FLUXNET Network (AmeriFlux, Fluxnet-Canada and Asia flux) for supporting flux data. We are grateful to Nobuko Saigusa at National Institute for Environmental Studies (NIES) for supporting Tomakomai dataset, Hiroaki Kondo and Shohei Murayama at National Institute of Advanced Industrial Science and Technology (AIST) for supporting Takayama dataset. We gratefully thank Yoshikazu Ohtani from Forestry and Forest Products Research Institute (FFPRI) for Fujiyoshida dataset and Takeshi Motohka from Phenological Eyes Network (PEN) for providing Takayama site's HSSR data. We acknowledge Institute for Basin Ecosystem Studies, Gifu University for providing precipitation data of JP-TKY in 2004. We thank Minoru Gamo from AIST, Samreong Panuthai from Department of National Parks, Wildlife and Plants Conservation, Thailand and Taksin Artchawakom from Sakaerat Environmental Research Station, Institute of Scientific and Technological Research (TISTR), Thailand for supporting Sakaerat dataset. We acknowledge Akira Miyata from National Institute for Agro-Environmental Sciences (NIAES) for Mase dataset. Authors would like to thank Ministry of Education, Culture, Sports, Science and Technology (MEXT) for supporting a scholarship. We acknowledge a project of Nara Women's University for partly research budget support. The authors also would like to thank anonymous reviewers who gave valuable suggestion that has helped to improve the quality of the manuscript.

\section{References}

1. Zhao, M.; Running, S.W. Drought-induced reduction in global terrestrial net primary production from 2000 through 2009. Science 2010, 329, 940-943.

2. Tanaka, K.; Okamura, Y.; Amano, T.; Hiramatsu, M.; Shiratama, K. Development status if the Second-generation Global Imager (SGLI) On GCOM-C1. Presented at SPIE Europe Security + Defence, Berlin, Germany, 31 August-3 September 2009.

3. Monteith, J. Solar radiation and production in tropical ecosystems. J. Appl. Ecol. 1972, 9, $747-766$. 
4. Heinsch, F.A.; Zhao, M.; Running, S.W.; Kimball, J.S.; Nemani, R.R.; Davis, K.J.; Bolstad, P.V.; Cook, B.D.; Desai, A.R.; Ricciuto, D.M.; et al. Evaluation of remote sensing based terrestrial productivity from MODIS using tower eddy flux network observations. IEEE Trans. Geosci. Remote Sens. 2006, 44, 1908-1925.

5. Wu, C.; Chen, J.M.; Desai, A.R.; Hollinger, D.Y.; Arain, M.A.; Margolis, H.A.; Gough, C.M.; Staebler, R.M. Remote sensing of canopy light use efficiency in temperate and boreal forests of North America using MODIS imagery. Remote Sens. Environ. 2012, 118, 60-72.

6. Coops, N.C.; Hilker, T.; Hall, F.G.; Nichol, C.J.; Drolet, G.G. Estimation of light-use efficiency of terrestrial ecosystems from space: A status report. BioScience 2010, 60, 788-797.

7. Potter, C.S.; Randerson, J.T.; Field, C.B.; Matson, P.A.; Vitousek, P.M.; Mooney, H.A.; Klooster, S.A. Terrestrial ecosystem production: A process model based on global satellite and surface data. Glob. Biogeochem. Cy. 1993, 7, 811-841.

8. Cramer, W.; Kicklighter, D.W.; Bondeau, A.; Moore, B.III.; Churkina, G.; Nemry, B.; Ruimy, A.; Schloss, A.L.; Participants of the Potsdam NPP Model Intercomparison. Comparing global models of terrestrial net primary production (NPP): Overview and key results. Global Change Biol. 1999, 5, 1-15.

9. Running, S.W.; Nemani, R.R.; Heinsch, F.A.; Zhao, M.; Reeves, M.; Hashimoto, H.A. Continuous satellite-derived measure of global terrestrial primary production. BioScience 2004, 54, 547-560.

10. Sasai, T.; Okamoto, K.; Hiyama, T.; Yamaguchi, Y. Comparing terrestrial carbon fluxes from the scale of a flux tower to the global scale. Ecol. Model. 2007, 208, 135-144.

11. Beer C.; Reichstein, M.; Tomelleri, E.; Ciais, P.; Jung, M.; Carvalhais, N., Rödenbeck, C.; Arain, M.A.; Baldocchi, D.; Bonan, G.B.; et al. Terrestrial gross carbon dioxide uptake: Global distribution and covariation with climate. Science 2010, 329, 834-838.

12. Jung, M.; Reichstein, M.; Bondeau, A. Towards global empirical upscaling of FLUXNET eddy covariance observation of a model tree ensemble approach using a biosphere model, Biogeoeciences 2009, 6, 2001-2013.

13. Zhang, F.; Chen, J.M.; Chen, J.; Gough, C.M.; Martin, T.A.; Dragoni, D. Evaluating spatial and temporal patterns of MODIS GPP over the conterminous U.S. against flux measurements and a process model. Remote Sens. Environ. 2012, 124, 717-729.

14. Chen, J.M., Liu, J., Cihlar, J., Guolden, M.L. Daily canopy photosynthesis model through temporal and spatial scaling for remote sensing applications. Ecol. Model. 1999, 124, 99-119.

15. Ryu, Y.; Baldocchi, D.D.; Kobayashi, H.; Ingen, C.V.; Li, J.; Black, A.T.; Beringer, J.; Gorsel, E.V.; Knohl, A.; Law, B.E.; Roupsard, O. Integration of MODIS land and atmosphere products with a coupled-process model to estimate gross primary productivity and evapotranspiration from $1 \mathrm{~km}$ to global scales. Glob. Biogeochem. Cy. 2011, 25, GB4017.

16. Muraoka, H.; Koizumi, H. Photosynthetic and structural characteristics of canopy and shrub trees in a cool-temperate deciduous broadleaved forest: Implication to the ecosystem carbon gain. Agric. Forest Meteorol. 2005, 134, 39-59. 
17. Muraoka, H. ; Saigusa, N.; Nasahara, K.N.; Noda, H.; Yoshino, J.; Saitoh, T.M.; Nagai, S.; Murayama, S.; Koizumi, H. Effects of seasonal and interannual variations in leaf photosynthesis and canopy leaf area index on gross primary production of a cool-temperate deciduous broadleaf forest in Takayama, Japan. J. Plant Res. 2010, 123, 563-576.

18. Houborg, R.; Anderson, M.C.; Norman, J.M.; Wilson, T.; Meyers, T. Intercomparison of a 'bottom-up' and 'top-down' modelling paradigm for estimating carbon and energy fluxes over a variety of vegetative regimes across the U.S. Agric. Forest Meteorol. 2009, 149, 2162-2182.

19. Reichstein, M.; Tenhunen, J.; Roupsard, O.; Ourcival, J.M.; Rambal, S.; Miglietta, F.; Peressotti, A.; Pecchiari, M.; Tirone, G.; Valentini, R. Inverse modeling of seasonal drought effects on canopy $\mathrm{CO}_{2} / \mathrm{H}_{2} \mathrm{O}$ exchange in three Mediterranean ecosystems. J. Geophys. Res. 2003, 108, 4726-4742.

20. Shibayama, M.; Akiyama, T.A. A spectroradiometer for field use: 6. Radiometric estimation for chlorophyll index of rice canopy. Jpn. J. Crop Sci. 1986, 55, 433-438.

21. Gamon, J.A.; Serrano, L.; Surfus, J.S. The photochemical reflectance index: an optical indicator of photosynthetic radiation use efficiency across species, functional types and nutrient levels. Oecologia 1997, 112, 492-501.

22. Inoue, Y.; Peñuelas, J.; Miyata, A.; Mano, M. Normalized difference spectral indices for estimating photosynthetic efficiency and capacity at a canopy scale derived from hyperspectral and $\mathrm{CO}_{2}$ flux measurements in rice. Remote Sens. Environ. 2008, 112, 156-172.

23. Gitelson, A.A.; Merzlyak, M.N. Quantitative estimation of chlorophyll-a using reflectance spectra: Experiments with autumn chestnut and maple leaves. J. Photochem. Photobiol. B: Biol. 1994, 22, 247-252.

24. Gitelson, A.; Merzlyak, M.N. Signature analysis of leaf reflectance spectra: Algorithm development for remote sensing of chlorophyll. J. Plant Physiol. 1996, 148, 494-500.

25. Gitelson, A.; Merzlyak, M. Remote estimation of chlorophyll content in higher plant leaves. Int. J. Remote Sens. 1997, 18, 291-298.

26. Gitelson, A.A.; Gritz, Y.; Merzlyak, M.N. Relationships between leaf chlorophyll content and spectral reflectance and algorithms for non-destructive chlorophyll assessment in higher plant leaves. J. Plant Physiol. 2003, 160, 271-282.

27. Gitelson, A.A.; Viña, A.; Arkebauer, T.J.; Rundquist, D.C.; Keydan, G.; Leavitt B. Remote estimation of leaf area index and green leaf biomass in maize canopies. Geophys. Res. Lett. 2003, $30,1248-1252$.

28. Gitelson, A.A.; Viña, A.; Rundquist, D.C.; Ciganda, V.; Arkebauer, T.J.; Remote estimation of canopy chlorophyll content in crops. Geophys. Res. Lett. 2005, 32, L08403-L08407.

29. Sims, D.A.; Luo, H.; Hastings, S.; Oechel, W.C.; Rahman, A.F.; Gamon, J.A. Parallel adjustments in vegetation greenness and ecosystem $\mathrm{CO}_{2}$ exchange in response to drought in a Southern California chaparral ecosystem. Remote Sens. Environ. 2006,103, 289-303.

30. Horler, D.N.H.; Dockray, M.; Barber, J.; The red edge of plant leaf reflectance. Int. J. Remote Sens. 1983, 4, 273-288.

31. Dash, J.; Curran, P.J. MTCI: The MERIS Teresrial Chlorophyll Index. In Proceeding of MERIS User Workshop, Frascati, Italy, 10-13 November 2003. 
32. Haboudane, D.; Miller, J.R.; Tremblay, N.; Zarco-Tejada, P.J.; Dextrase, L. Integrated narrow-band vegetation indices for prediction of crop chlorophyll content for application to precision agriculture. Remote Sens. Environ. 2002, 81, 416-426.

33. Huete, A.R. A soil adjusted vegetation index (SAVI). Remote Sens. Environ. 1988, 25, 295-309.

34. Rondeaux, G.; Steven, M.; Baret, F. Optimization of soil-adjusted vegetation indices. Remote Sens. Environ. 1996, 55, 95-107.

35. Daughtry, C.S.T.; Walthall, C.L.; Kim, M.S.; de Colstrum, E.B.; McMurtrey, J.E., III. Estimating corn leaf chlorophyll concentration from leaf and canopy reflectance. Remote Sens. Environ. 2000, 74, 229-239.

36. Wu, C.; Niu Z.; Tang, Q.; Huang, W. Estimating chlorophyll content from hyperspectral vegetation indices: Modeling and validation. Agric. Forest Meteorol. 2008, 148, 1230-1241.

37. Gitelson, A.A.; Viña, A.; Verma, S.; Rundquist, D.C.; Arkebauer, T.J.; Keydan, G.; Leavitt, B.; Ciganda, V.; Burba, G.G.; Suyker, A.E. Relationship between gross primary production and chlorophyll content in crops: Implications for the synoptic monitoring of vegetation productivity. J. Geophys. Res. 2006, 111, D08S11.

38. Wu, C.; Niu, Z.; Tang, Q.; Huang, W.; Rivard, B.; Feng, J. Remote estimation of gross primary production in wheat using chlorophyll-related vegetation indices. Agric. Forest Meteorol. 2009, 149, 1015-1021.

39. Wu, C.; Wang, L.; Niu, Z.; Gao, S.; Wu, M.Q. Nondestructive estimation of canopy chlorophyll content using Hyperion and Landsat/TM images. Int. J. Remote Sens. 2010, 31, 2159-2167.

40. Wu, C.; Niu, Z.; Gao, S. The potential of the satellite derived green chlorophyll index for estimating midday light use efficiency in maize, coniferous forest and grassland. Ecol. Indic. 2012, 14, 66-73.

41. Gitelson, A.A.; Peng, Y.; Masek, J.G.; Rundquist, D.C.; Verma, S.; Suyker, A.; Baker, J.M.; Hatfield, J.L.; Meyers, T. Remote estimation of crop gross primary production with Landsat data, Remote Sens. Environ. 2012, 121, 404-414.

42. Wu, C.; Chen, J.M.; Huang, N. Predicting gross primary production from the enhanced vegetation index and photosynthetically active radiation: Evaluation and calibration. Remote Sens. Environ. 2011, 115, 3424-3435.

43. Xiong, Y.A. Study on Algorithm for Estimation of Global Terrestrial Net Primary Production using Satellite Sensor Data. Ph.D. Dissertation, The Division of Integrated Sciences, Nara Women's University, Nara, Japan, 2005.

44. Furumi, S.; Xiong, Y.; Fujiwara, N. Establishment of an Algorithm to Estimate Vegetation Photosynthesis by Pattern Decomposition Using Multi-Spectral Data. J. Remote Sens. Soc. Jpn. 2005, 25, 47-59.

45. Muramatsu, K.; Furumi, S.; Chen, L.; Xiong, Y.; Daigo, M. Estimation and Validation of Net Primary Production of Vegetation using ADEOS-II/GLI data Global Mosaic and 250-m Spatial Resolution Data. J. Remote Sens. Soc. Jpn. 2009, 29, 114-123.

46. Ide, R.; Nakaji, T.; Oguma, H. Assessment of canopy photosynthetic capacity and estimation of GPP by using spectral vegetation indices and the light-response function in a larch forest. Agric. Forest Meteorol. 2010, 150, 389-398. 
47. Sellers, P.J.; Berry, J.A.; Collatz, G.J.; Field, C.B.; Hall, F.G. Canopy reflectance, photosynthesis, and transpiration. III. A reanalysis using improved leaf models and a new canopy integration scheme. Remote Sens. Environ. 1992, 42, 187-216.

48. Taiz, L.; Zeiger, E. Photosynthesis: The Carbon Reactions. In Plant Physiology, 4th ed.; Chapter 8; Sinauer Associates, Inc.: Sunderland, MA, USA, 2006.

49. Jones, H.G.; Vaugha, R.A. Use of Spectral Information for Sensing Vegetation Properties and for Image Classification. In Remote Sensing of Vegetation: Principles, Techniques, and Applications; Chapter 7; Oxford University Press: New York, NY, USA, 2010; pp. 169-170.

50. Gitelson, A. A.; Kaufman, Y.J.; Merzlyak, M.N. Use of a green channel in remote sensing of global vegetation from EOS-MODIS. Remote Sens. Environ. 1996, 58, 289-298.

51. Nagai, S.; Saigusa, N.; Muraoka, H.; Nasahara, K.N. What makes the satellite-based EVI-GPP relationship unclear in a deciduous broad-leaved forest? Ecol. Res. 2010, 25, 359-365.

52. Lambers, H.; Chapin, FS III.; Pons, TL. Plant Physiological Ecology, 2nd ed., Springer: New York, NY, USA, 2008; p. 27.

53. Ono, K.; Hashimoto, H.; Katoh, S. Changes in the number and size of chloroplasts during senescence of primary leaves of wheat grown under different conditions. Plant Cell Physiol. 1995, $36,9-17$.

54. Oguchi, R.; Hikosaka, K.; Hirose, T. Does the photosynthetic light-acclimation need change in leaf anatomy? Plant Cell Environ. 2003, 26, 505-512.

55. Rouse, J.W.; Haas, R.H.; Deering, D.W.; Schell, J.A. Monitoring the Vernal Advancement and Retro Gradation (Green Wave Effect) of Natural Vegetation; Final Report, Remote Sensing Center, Texas A\&M University: College Station, TX, USA, 1974.

56. Huete, A.; Didan, K.; Miura, T.; Rodriguez, E.P.; Gao, X.; Ferreira, L.G. Overview of the radiometric and biophysical performance of the MODIS vegetation indices. Remote Sens. Environ. 2002, 83, 195-213.

57. Sims, D.A.; Gamon, J.A. Relationships between leaf pigment content and spectral reflectance across a wide range of species, leaf structures and developmental stages. Remote Sens. Environ. 2002, 81, 337-354.

58. Tucker, C.J. Red and photographic infrared linear combinations for monitoring vegetation. Remote Sens. Environ. 1979, 8, 127-150.

59. Jordan, C.F. Derivation of leaf area index from quality of light on the forest floor. Ecology 1969, 50, 663-666.

60. Furumi, S.; Hayashi, A.; Muramatsu, K.; Fujiwara, N. Relation between vegetation vigor and a new vegetation index based on pattern decomposition method. J. Remote Sens. Soc. Jpn. 1998, 18, $17-34$.

61. Nishida, K. Phenological Eyes Network (PEN): A validation network for remote sensing of the terrestrial ecosystems. Asia-Flux Newsletter 2007, 21, 9-13.

62. Bonan, G. A Land Surface Model (LSM version 1.0) for Ecological, Hydrological, and Atmospheric Studies: Technical Description and User's Guide; NCAR: Boulder, CO, USA, 1996.

63. Forestry and Forest Products Research Institute. FFPRI FluxNet Database, 2010. Available online: http://www.ffpri.affrc.go.jp/labs/flux/index.html (accessed on 14 November 2012). 
64. The NASA-developed Earth Observing System (EOS) Clearinghouse (ECHO). Available online: http://reverb.echo.nasa.gov/reverb/\#utf8=\%E2\%9C\%93\&spatial_map=satellite\&spatial_type=rect angle (accessed on 14 November 2012).

65. Reichstein, M.; Falge, E.; Baldocchi, D.; Papale, D.; Aubinet, M.; Berbigier, P.; Bernhofer, C.; Buchmann, N.; Gilmanov, T.; Granier, A.; et al. On the separation of net ecosystem exchange into assimilation and ecosystem respiration: review and improved algorithm. Global Change Biol. 2005, 11, 1424-1439.

66. Baldocchi, D.; Falge, E.; Wilson, K. A spectral analysis of biosphere-atmosphere trace gas flux densities and meteorological variables across hour to multi-year time scales. Agric. Forest Meteorol. 2001, 107, 1-27.

67. Pathre, U.; Sinha, A.K.; Shirke, P.A.; Sane, P.V. Factors determining the midday depression of photosynthesis in trees under monsoon climate. Trees 1998, 12, 472-481.

68. Pessarakli, M. Handbook of Photosynthesis, 2nd ed.; CRC Press: Boca Raton, FL, USA, 2005; p. 287.

69. Thomas, J.R.; Gausman, H.W. Leaf reflectance vs. leaf chlorophyll and carotenoid concentrations for eight crops. Agron. J. 1977, 69, 799-802.

70. Chappelle, E.W.; Kim, M.S.; McMurtrey III.J.E. Ratio analysis of reflectance spectra (RARS): An algorithm for the remote estimation of the concentrations of chlorophyll A, chlorophyll B, and carotenoids in soybean leaves. Remote Sens. Environ. 1992, 39, 239-247.

71. Gitelson A.A.; Chivkunova O.B.; Merzlyak M. N. Nondestructive estimation of anthocyanins and chlorophylls in anthocyanic leaves. Am. J. Bot. 2009, 96, 1861-1868.

72. Datt, B. Remote sensing of chlorophyll a, chlorophyll b, chlorophyll $a+b$, and total carotenoid content in Eucalyptus leaves. Remote Sens. Environ. 1998, 66, 111-121.

73. Buschman, C.; Nagel, E. In vivo spectroscopy and internal optics of leaves as a basis for remote sensing of vegetation. Int. J. Remote Sens. 1993, 14, 711-722.

74. Datt, B.A new reflectance index for remote sensing of chlorophyll content in higher plants: Tests using Eucalyptus leaves. J. Plant Physiol. 1999, 154, 30-36.

75. Yoder, B.J.; Waring, R.H. The normalized difference vegetation index of small Douglas-fir canopies with varying chlorophyll concentrations. Remote Sens. Environ. 1994, 49, 81-91.

76. Gilmanov, T.G.; Tieszen, L.L.; Wylie, B.K.; Flanagan, L.B.; Frank, A.B.; Haferkamp M.R.; Meyers, T.P.; Morgan, J.A. Integration of $\mathrm{CO}_{2}$ flux and remotely-sensed data for primary production and ecosystem respiration analyses in the Northern Great Plains: Potential for quantitative spatial extrapolation. Global Ecol. Biogeogr. 2005, 14, 271-292.

77. Saigusa, N.; Yamamoto, S.; Hirata, R.; Ohtani, Y.; Ide, R.; Asanuma, J.; Gamo, M.; Hirano, T.; Kondo, H.; Kosugi, Y.; Li, S.G.; Nakai, Y.; Takagi, K.; Tani, M.; Wang, H. Temporal and spatial variations in the seasonal patterns of $\mathrm{CO} 2$ flux in boreal, temperate, and tropical forests in East Asia. Agric. Forest Meteorol. 2008, 148, 700-713.

78. Saito, M.; Maksyutov, S.; Hirata, R.; Richardson, A.D. An empirical model simulating diurnal and seasonal $\mathrm{CO}_{2}$ flux for diverse vegetation types and climate conditions. Biogeosciences 2009, 6, 585-599. 
79. Takeda, T.; Yajima, M. An improvement of semiempirical method for estimating the total photosynthesis of the crop population: I. On light-photosynthesis curve of rice leaves (in Japanese). Jpn. J. Crop Sci. 1975, 44, 343-349.

80. Ruimy, A.; Javis, P.G.; Baldocchi, D.D.; Saugier, B. $\mathrm{CO}_{2}$ fluxes over plant canopies and solar radiation: a review. Adv. Ecol. Res. 1995, 26, 1-69.

81. Xiao, X. Light absorption by leaf chlorophyll and maximum light use efficiency. IEEE Trans. Geosci. Remote Sens. 2006, 44, 1933-1935.

82. Owen, K.; Tenhunen, J.; Reichstein, M.; Wang, Q.; Falge, E.; Geyer, R.; Xiao, X.; Stoy, P.; Mann, C.; Arain, A.; et al. Linking flux network measurements to continental scale simulations: ecosystem carbon dioxide exchange capacity under non-water-stressed conditions. Global Change Biol. 2007, 13, 734-760. Rahman, A. F.; Sims, D. A.; Cordova, V. D.; El-Masri, B. Z. Potential of MODIS EVI and surface temperature for directly estimating per-pixel ecosystem $\mathrm{C}$ fluxes. Geophys. Res. Lett. 2005, 32, L19404.

84. Xiao, X.; Hollinger, D.; Aber, J.; Goltz, M.; Davidson, E.A.; Zhang, Q.; Moore, B., III. Satellite-based modeling of gross primary production in an evergreen needle leaf forest. Remote Sens. Environ. 2004, 89, 519-534.

85. Xiao, X.; Zhang, Q.; Braswell, B.; Urbanski, S.; Boles, S.; Wofsy, S.; et al. Modeling gross primary production of temperate deciduous broadleaf forest using satellite images and climate data. Remote Sens. Environ. 2004, 91, 256-270.

86. Huete, A.R.; Didan, K.; Shimabukuro, Y.E.; Ratana, P.; Saleska, S.R. Amazon rainforests greenup with sunlight in dry season. Geophys. Res. Lett. 2006, 33, L06405.

87. Stoy, P. Personal Communication, 2010.

88. Aguilos, M.M.; Gamo, M.; Maeda, T. Carbon budget of some tropical and temperate forest. Asia-Flux Newsletter 2007, Special Issue, 18-22.

89. Huete, A.R.; Restrepo-Coupe, N., Ratana, P.; Didan, K.; Saleska, S.R.; Ichii, K.; Panuthai S.; Gamo, M. Multiple site tower flux and remote sensing comparisons of tropical forest dynamics in Monsoon Asia. Agric. Forest Meteorol. 2008, 148, 748-760.

90. Ohtani, Y.; Saigusa, N.; Yamamoto, S.; Mizoguchi, Y.; Watanabe, T.; Yasuda, Y.; Murayama, S. Characteristics of $\mathrm{CO}_{2}$ fluxes in cool-temperate coniferous and deciduous broadleaf forests in Japan. Phyton 2005, 45, 73-80.

91. Hashimoto, H.; Wang, W.; Milesi, C.; White, M.A.; Ganguly, S.; Gamo, M.; Hirata, R.; Myneni, R.B.; Nemani, R.R. Exploring simple algorithms for estimating gross primary production in forested areas from satellite data. Remote Sens. 2012, 4, 303-326.

92. Chen, J.M.; Mo, G.; Pisek, J.; Liu, J.; Deng, F.; Ishizawa, M.; Chan D., Effects of foliage clumping on the estimation of global terrestrial gross primary productivity, Glob. Biogeochem. Cy. 2012, 26, GB1019.

93. Thanyapraneedkul, J.; Muramatsu, K.; Daigo, M.; Furumi, S.; Soyama, N. Improvement of Terrestrial GPP Estimation Algorithms Using Satellite and Flux Data. In Proceedings of ISPRS Technical Commission VIII Symposium "Networking the World with Remote Sensing”, Kyoto, Japan, 9-12 August 2010; pp. 814-819. 


\section{Appendix}

GPP data derived from EC flux data were used to calculate $\mathrm{P}_{\text {max }}$ capacity2000. If GPP data were not available from flux projects, we could calculate GPP using respiration data [1].

\section{Respiration (Rec) Estimation for the GPP Estimation}

GPP is calculated using the NEP data plus ecosystem respiration $(\mathrm{Rec})$ as

$$
\mathrm{GPP}=\mathrm{NEP}+\operatorname{Rec}\left(\mathrm{T}_{\mathrm{air}}\right)
$$

where Rec is the plant respiration plus soil respiration as a function of air temperature $\left(\mathrm{T}_{\text {air }}\right)$.

We determined the nighttime Rec [2], i.e., the nighttime NEE, as an exponential function of $\mathrm{T}_{\text {air }}$ and applied the function to the daytime data to estimate daytime Rec using the following simple exponential function:

$$
\operatorname{Rec}=A \exp \left(B \times \mathrm{T}_{\text {air }}\right)
$$

where $A$ and $B$ are empirical constants to be determined by regression, $B$ is related to the temperature coefficient, and $A$ is Rec at $0{ }^{\circ} \mathrm{C}$.

Equation (A2) is an empirical formula expressing the relationship between the $\mathrm{T}_{\text {air }}$ and Rec at sites measured by the EC method under nearly neutral atmospheric stability using $U^{*}$ filtering to avoid the flux underestimation on stable nights caused by friction velocity [1]. $U^{*}$ threshold values are site-specific values and are summarized in Table 2. The threshold values are $0.1 \mathrm{~m} \cdot \mathrm{s}^{-1}$ for JP-Mase [2]; $0.12 \mathrm{~m} \cdot \mathrm{s}^{-1}$ for JP-FJY [3]; $0.2 \mathrm{~m} \cdot \mathrm{s}^{-1}$ for CA-Let [76], US-Dk1 [4] and TH-SKR [89]; $0.3 \mathrm{~m} \cdot \mathrm{s}^{-1}$ for JP-TMK [5]; and $0.5 \mathrm{~m} \cdot \mathrm{s}^{-1}$ for JP-TKY [6]. For JP-TMK, the respiration curve used the soil temperature at $5 \mathrm{~cm}$, instead of $\mathrm{T}_{\text {air }}[5]$.

\section{Respiration Curve}

GPP was calculated using the NEP daytime and respiration estimation results. To estimate respiration, the NEP nighttime data were used (NEP < zero). We excluded NEP nighttime data with more than zero precipitation because soil water may affect the respiration rate. Figure A1(a-f) shows the relationship between the nighttime NEP and $\mathrm{T}_{\text {air }}$ for CA-Let, JP-TKY2004, JP-Mase, JP-FJY, and TH-SKR, respectively. At the JP-TMK site [Figure A1(b)], we used $\mathrm{T}_{\text {soil }}$ instead of $\mathrm{T}_{\text {air }}$. The value of Rec had a significant positive correlation with $\mathrm{T}_{\text {air }}$. The relationships were more exponential than linear, as shown in Figure A1. Figure A1 shows the least-square fitting lines for $\mathrm{T}_{\text {air }}$ or $\mathrm{T}_{\text {soil }}$ and nighttime NEP with an exponential equation. The lowest Rec was found at CA-Let, which is located in the arctic zone [Figure A1(a)]. The highest Rec was at TH-SKR, which is located in the tropical zone [Figure A1(f)]. The relationship for the TH-SKR site was not good because we did not apply Van Gorsel's filtering instead of $U^{*}$ filtering to obtain a better correlation [77]. 
Figure A1. Ecosystem respiration (Rec), i.e., the relationship between air/soil temperature and nighttime NEP (NEP <0): (a) CA-Let, (b) JP-TMK, (c) JP-TKY2004, (d) JP-Mase, (e) JP-FJY, and (f) TH-SKR.

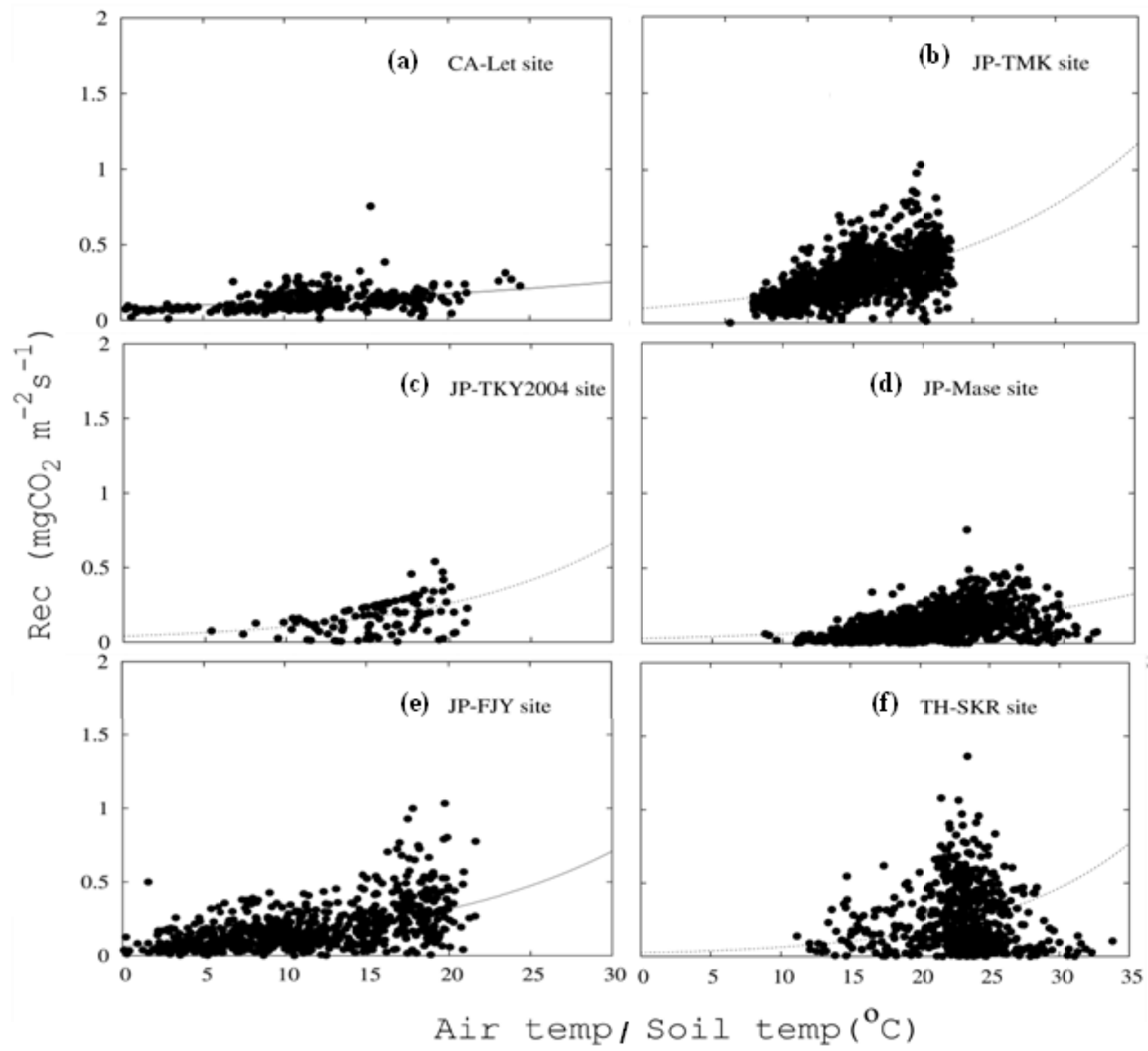

\section{References}

1. Saigusa, N.; Yamamoto, S.; Murayama, S.; Kondo, H. Inter-annual variability of carbon budget components in an AsiaFlux forest site estimated by long-term flux measurements. Agric. Forest Meteorol. 2005, 134, 4-16.

2. Saito, M.; Miyata, A.; Nagai, H.; Yamada, T. Seasonal variation of carbon dioxide exchange in rice paddy field in Japan. Agric. Forest Meteorol. 2005, 135, 93-109.

3. Mizoguchi, Y.; Ohtani, Y.; Takanashi, S.; Iwata, H.; Yasuda, Y.; Nakai, Y. Seasonal and interannual variation in net ecosystem production of an evergreen needleleaf forest in Japan. $J$. Forest Res. 2012, 17, 283-295.

4. Novick, K.A.; Stoy, P.C.; Katul, G.G.; Ellsworth, D.S.; Siqueira, M.B.S.; Juang, J.; Oren, R. Carbon dioxide and water vapor exchange in a warm temperate grassland. Oecologia 2004, 138, 259-274. 
5. Hirata, R.; Hirano, T.; Saigusa, N.; Fujinuma, Y.; Inukai, K.; Kitamori, Y.; Takahashi, Y.; Yamamoto, S. Seasonal and interannual variations in carbon dioxide exchange of a temperate larch forest. Agric. Forest Meteorol. 2007, 147, 110-124.

6. Hirata, R.; Saigusa, N.; Yamamoto, S.; Ohtani, Y.; Ide, R.; Asanuma, J.; Gamo, M.; Hirano, T.; Kondo, H.; Kosugi, Y.; et al. Spatial distribution of carbon balance in forest ecosystems across East Asia. Agric. Forest Meteorol. 2008, 148, 761-775.

(C) 2012 by the authors; licensee MDPI, Basel, Switzerland. This article is an open access article distributed under the terms and conditions of the Creative Commons Attribution license (http://creativecommons.org/licenses/by/3.0/). 